\title{
RECURSOS FITOGENÉTICOS FORESTALES, FORRAJEROS, DE INTERÉS APÍCOLA Y PAISAJÍSTICO NATIVOS DE LA PROVINCIA DE SANTA FE (ARGENTINA)
}

\author{
Zabala, J. M. ${ }^{1}$; Exner, E. ${ }^{1} ;$ Cerino, C. ${ }^{1} ;$ Buyatti, M. ${ }^{4}$; \\ Cuffia, C. ${ }^{1,2} ;$ Marinoni, L. ${ }^{1,2} ;$ Kern, V. ${ }^{1}$ \& Pensiero, J. F. ${ }^{1,2}$ (EX AeQuo)
}

\begin{abstract}
RESUMEN
Santa Fe posee un número significativo de especies nativas con valor real o potencial para la producción agropecuaria, industrial y la protección ambiental. El primer paso para desarrollar una estrategia de uso eficiente de los recursos genéticos silvestres es el listado de las especies prioritarias a conservar. En este trabajo se analizan los recursos fitogenéticos forrajeros herbáceos, forestales, de interés apícola y paisajístico dada su importancia económica y/o estratégica. Se brinda información de uso en cada categoría y en todas las especies se analiza su distribución geográfica por departamentos y se presenta información sobre la conservación de sus semillas. Se priorizaron 138 especies, 29 de las cuales tienen más de un uso (24 de interés forestal, 45 de interés forrajero, 32 de interés apícola y 69 de interés paisajístico). La información que se presenta será de utilidad en el diseño de estrategias de conservación y uso de los recursos fitogenéticos nativos por parte de investigadores y organismos oficiales provinciales y nacionales.
\end{abstract}

Palabras clave: Recursos fitogenéticos silvestres, conservación ex situ, bancos de germoplasma.

1.- Facultad de Ciencias Agrarias, Universidad Nacional del Litoral. Kreder 2805. 3080HOF, Esperanza, Santa Fe, Argentina. Email: jmzabala@fca.unl.edu.ar

2.- FCA (UNL) - Consejo Nacional de Investigaciones Científicas y Técnicas.

Manuscrito recibido el 27 de abril de 2020 y aceptado para su publicación el 11 de septiembre de 2020.

Zabala JM, Exner E, Cerino C, Buyatti M, Cuffia C, Marinoni L, Kern V, Pensiero JF. Recursos fitogenéticos forestales, forrajeros, de interés apícola y paisajístico nativos de la provincia de Santa Fe (Argentina). FAVE - Ciencias Agrarias 20 (1): 99-131. CC BY-NC-SA 4.0 


\begin{abstract}
Forest, forage, beekeeping and landscape plant genetic resources native from Santa Fe province (Argentina).

Santa Fe has a significant number of native species with real or potential value for agricultural, industrial production and environmental protection. The first step in developing a strategy for efficient use of wild genetic resources is the listing of priority species to conserve. In this work, plants with herbaceous forage, forest, beekeepping and landscape interest are analyzed. Information on use is provided in each category and, for all species the geographical distribution by departments is analyzed and information about seed conservation is presented. Thus, 138 species were prioritized, 29 of which have more than one use (24 of forest interest, 45 of forage interest, 32 of beekeeping interest and 69 of landscape interest). The information presented will be useful in the design of strategies for the conservation and use of wild plant genetic resources by researchers and the government.
\end{abstract}

Key words: Wild plant genetic resources, ex situ conservation, germplasm banks.

\section{INTRODUCCIÓN}

En la diversidad biológica presente en la naturaleza existe un número significativo de especies consideradas recursos genéticos, los cuales se definen como "todo material genético de origen vegetal, animal, microbiano o de otro tipo que contenga unidades funcionales de la herencia con valor real o potencial" (Convenio de Diversidad Biológica 1992). En dicho contexto, los recursos fitogenéticos comprenden la diversidad genética correspondiente al mundo vegetal que se considera poseedora de un valor para el presente o el futuro de la humanidad.

Los recursos fitogenéticos nativos debieran considerarse un tipo de "recursos de uso común”, es decir bienes que una comunidad o sociedad usan cooperativametne (Ostrom, 2009a). Bajo esta lógica, cualquier derecho de propiedad intelectual que pueda surgir debería enmarcarse en una política de sustentabilidad y distribución equitativa del beneficio de su uso. Sin embargo, y a pesar de los múltiples acuerdos internacionales que ava- lan esa política, estamos ante un escenario mundial de pérdida de biodiversidad y conflictos relacionados con la propiedad y uso de los recursos biológicos en general (Ostrom, 2009b) y de los recursos fitogenéticos en particular (Girard y Frison, 2018; Wolter y Sievers-Glotzbach, 2019; Sievers-Glotzbach et al., 2020). En el caso de los recursos fitogenéticos existen múltiples estrategias para lograr esos objetivos, como lo son los bancos de semillas comunitarios (de Boef et al., 2013; Vernooy et al., 2017), programas de mejoramiento abiertos y colaborativos (Li et al, 2014; Wolter y Sievers-Glotzbach, 2019; Cremaschi y van Zwanenberg, 2020) y sistemas cooperativos de producción de semillas de especies nativas (Zabala et al., 2015; Smith, 2017), entre otros.

Existen diferentes categorías de recursos fitogenéticos, una de ellas corresponde a 'especies silvestres’. Éstas pueden ser utilizadas en planes de restauración de ambientes naturales o introducirlas a cultivo para diferentes usos: alimenticio, forrajero, forestal, materia prima industrial, entre otros (citas).(Khoury 
et al., 2019; Singh et al., 2019). Muchas de estas especies tienen importancia regional o local. A pesar de su valor económico o cultural, están muy poco representadas en colecciones ex situ (Khoury et al., 2019).

La utilización de los recursos fitogenéticos se basa en programas a largo plazo de colecta, conservación y evaluación agronómica. Además, se requiere un uso sostenible de los mismos y una distribución equitativa de los beneficios que generen. Estos aspectos han sido abordados en la legislación internacional como el Convenio de Diversidad Biológica (adhesión de Argentina a través de la Ley 24375), el Protocolo de Nagoya (aprobado en Argentina por Ley 27246) y el Tratado Internacional sobre los Recursos Fitogenéticos para la Alimentación y la Agricultura (TIRFAA) de la FAO (aprobado en Argentina por Ley 27182). En particular para nuestro país, la Constitución Nacional, reformada en 1994, en su Artículo 124 indica que "corresponde a las provincias el dominio originario de los recursos naturales existentes en su territorio”. Sin embargo, solo 8 de las 23 provincias argentinas tienen una legislación relacionada con el acceso a los recursos genéticos (Silvestri, 2015). Paralelamente, no existe una legislación nacional que indique los presupuestos mínimos acerca del acceso a los recursos naturales, en particular a los recursos genéticos, como lo indica el Artículo 41 de la Constitución Nacional. Tampoco existen listas priorizadas de los recursos fitogenéticos de cada provincia. El primer paso para desarrollar una estrategia de uso eficiente de los recursos genéticos silvestres es el listado de las especies prioritarias a conservar, a través de un trabajo interdisciplinario y con uso de bases de datos confiables para un correcto análisis taxonómico y de factibilidad de conservación ex situ (Khoury et al., 2019).
La provincia de Santa Fe posee una importante riqueza florística, representada por 1969 taxones (Pensiero et al., 2005), entre los que existen un número significativo de especies silvestres con valor real o potencial para la producción agropecuaria e industrial. Los recursos fitogenéticos silvestres (incluyendo entre ellos a las especies nativas y naturalizadas) son el producto de un largo proceso de selección natural y adaptación a las variaciones del ambiente (Endler, 1986; Street et al., 2016). Estas especies poseen mecanismos genéticos únicos que les permiten crecer y desarrollarse en cada uno de los ambientes de origen (Basey et al., 2015).

En la Facultad de Ciencias Agrarias, y en el marco del Programa de Documentación, Conservación y Valoración de la Flora Nativa (PRODOCOVA), se llevan adelante diferentes estrategias relativas a la documentación, conservación y uso de nuestros recursos fitogenéticos (http://www.fca.unl. edu.ar/prodocova/index), a través de dos colecciones biológicas resguardadas en el Herbario "Arturo E. Ragonese” y en el Banco de Germoplasma “Ing. Agr. José Mario Alonso".

En el presente trabajo se realiza un análisis crítico de algunas especies nativas que constituyen recursos fitogenéticos de la provincia de Santa Fe, y que en la actualidad son subutilizados o no utilizados. Se analizan los recursos fitogenéticos forrajeros herbáceos, forestales, de interés apícola y paisajístico dada su importancia económica y/o estratégica a nivel provincial. Se han priorizado aquellas especies que, a nuestro criterio, con la información ya disponible, o con la que se pudiera generar a corto o mediano plazo, se podrían introducir a cultivo. 


\section{Recursos genéticos forestales}

Buena parte del desarrollo económico y social del norte de la provincia de Santa Fe se relacionó directamente con la explotación de especies forestales en su estado natural, en particular del "quebracho colorado” (Schinopsis balansae) (Gori, 1965), seguida por otras especies forestales valiosas, como los “algarrobos" (Prosopis sp.) (Palacios y Brizuela, 2005). La sobreexplotación de nuestros recursos forestales, junto con el avance de la frontera agrícola, produjeron una reducción drástica de la superficie boscosa, con la consecuente reducción de su diversidad genética. En relación con esto, en el período 1994-2006, se deforestaron en la provincia de Santa Fe 91.323 ha (Servicio de Catastro e Información Territorial, 2007). Un reflejo de la sobreexplotación que presentan actualmente los bosques remanentes de la Cuña Boscosa lo representa el consumo de 750.000 toneladas de leña fundamentalmente por parte de la industria local y en menor medida por sus pobladores (Zarrilli, 2018). Dicha leña, históricamente se obtuvo de los mejores ejemplares de las especies nativas, produciéndose una reducción de la diversidad genética dentro de las especies y el valor ambiental de los bosques.

Actualmente, el número de fábricas de la industria de la madera de la región centro de Argentina, que incluye las provincias de Córdoba, Santa Fe y Entre Ríos, representa el 50\% del total nacional. La provincia de Santa Fe ocupa el segundo lugar, luego de Buenos Aires, en la industrialización primaria y secundaria de la madera. En el centro de la provincia de Santa Fe es de particular importancia la industria del mueble, con más de 400 fábricas. En el año 2009, el $54 \%$ de la madera utilizada por esta industria fue de algarrobo (Prosopis sp.). En los últimos años, debido a la sobreexplotación de los bosques nativos, el uso de esta madera ha declinado (Piattoni, 2010). Si bien la estrategia actual es incrementar el uso de maderas exóticas provenientes de forestaciones cultivadas, existe una oportunidad para la introducción a cultivo de algunas especies forestales nativas. Por otro lado, la aplicación en Santa Fe de la Ley 26.331 (conocida como de Presupuestos Mínimos de Protección Ambiental de los Bosques Nativos) propicia el enriquecimiento de los bosques incorporando especies nativas. En tal sentido, en el caso de planes de enriquecimiento se deberían usar especies y poblaciones (germoplasma) propias de la zona o región a enriquecer (Basey et al., 2015).

Teniendo como base el mapa de Ordenamiento Territorial de Bosques Nativos (OTBN) de la provincia de Santa Fe (https:// www.santafe.gob.ar/datosabiertos/dataset/ mapa-de-ordenamiento-de-bosques-nativos), en el marco del Programa de Documentación, Conservación y Valoración de la flora nativa se identificaron importantes áreas boscosas en buen estado de conservación, en las que se iniciaron planes de colecta y conservación de germoplasma de especies y ejemplares forestales valiosos.

En este trabajo se presentan las especies con valor forestal maderero, excluyéndose otros usos como frutas comestibles u otros productos forestales no madereros, los que dado su valor deberían ser abordados en otros trabajos.

\section{Recursos genéticos forrajeros \\ herbáceos}

La producción agropecuaria contribuye con el 13,6\% del valor económico agregado provincial y representa el 27,5\% del producto bruto geográfico del sector de producción de bienes (Santangelo y Gil, 2016). La producción ganadera en particular aporta 
aproximadamente el 10\% de las exportaciones provinciales, siendo la producción de carne una de las más importantes, con un stock bovino que representa el $12 \%$ de las existencias del país (6,2 millones de cabezas), el segundo en importancia después de Buenos Aires (Santangelo y Gil, 2016). La ganadería de carne del centro y norte de la provincia representa el 57\% del stock provincial. En esta región existen 5.000.000 de has de pastizales y bosques (88\% y 12\%, respectivamente) que son la base forrajera de la ganadería (Ministerio de Producción de la Provincia de Santa Fe, 2009). Estos ambientes poseen una alta riqueza florística, y muchas de sus especies constituyen valiosos recursos forrajeros (Pensiero, 2017).

En este trabajo presentamos las especies forrajeras nativas herbáceas gramíneas y leguminosas, con potencialidad para su introducción a cultivo o uso en planes de restauración de pastizales, con el objetivo de incrementar la cantidad y calidad de la oferta forrajera. Se han priorizado, además, especies de leguminosas que puedan incorporar nitrógeno al suelo a través de su fijación biológica. El uso de estas especies, combinadas con otras estrategias como el manejo correcto de los pastizales y la suplementación estacional, podrían incrementar los bajos niveles actuales de productividad ganadera que posee la provincia (Ministerio de Producción de la Provincia de Santa Fe, 2009).

\section{Recursos genéticos de interés apícola}

La apicultura en Argentina es una actividad de relevancia ya que el $80-90 \%$ de la producción se exporta, generando aproximadamente U\$S 200.000.000 anuales (Ministerio de la producción 2008, Vazquez y Castignani, 2018). Entre 2014 y 2018, Argentina ocupó el primer lugar del Mercosur como exportador de productos de la colmena hacia la Unión Europea (21123 toneladas que representaron el 71\% de la producción conjunta con Brasil y Uruguay) (Vazquez y Castignani, 2019). Desarrollada principalmente como actividad complementaria, la provincia de Santa Fe es el tercer productor a nivel nacional luego de Buenos Aires y Entre Ríos, con 235 a 255 mil colmenas (Magyp, 2019). A lo largo del territorio provincial, la actividad se encuentra enmarcada en la ley provincial $N^{\circ} 13870$ de promoción, protección y desarrollo de la actividad apícola en la provincia de Santa Fe.

A nivel nacional, la producción apícola sufrió en los últimos años una importante reducción en la productividad (Rabaglio et al., 2015). Entre las principales debilidades de la actividad se encuentra una baja disponibilidad de recursos florales diversos y de calidad. Esta falta de flores se asocia, principalmente, al avance de la agricultura y a otras prácticas actuales de uso de la tierra que derivan en fragmentación y degradación de hábitat (Ollerton et al., 2014, Goulson et al., 2015). El efecto negativo de esta situación se acentúa en el período otoño-invernal, dónde la oferta floral natural es escasa a nula, y en áreas agrícola-ganaderas florísticamente empobrecidas dónde la oferta es estacional, homogénea y de baja calidad. El enriquecimiento de ambientes naturales y semi-naturales (apiarios, plantaciones frutales, bordes de rutas y caminos rurales) con especies melíferas nativas surge como una herramienta sustentable para mejorar la oferta de recursos para las abejas (Decourtye et al., 2010; Vaudo et al., 2015; Danner et al., 2016). En este sentido resulta indispensable la priorización, el estudio y la conservación de especies nativas promisorias como fuente de recursos alimenticios y de nidificación para las abejas’. 
Las especies nativas de la flora argentina constituyen el principal aporte de recursos florales para Apis mellifera L. en diferentes ecorregiones del país (Tellería, 1995; Basilio y Romero, 1996; Basilio y Noetinger, 2002; Andrada, 2003; Caccavari y Fagúndez, 2010; Fagúndez, 2011; Sánchez y Lupo, 2011; Cabrera et al., 2013; Salgado et al., 2014), y un gran número de ellas habita en la provincia de Santa Fe (Pensiero et al., 2005). Del conjunto de especies nativas utilizadas como recursos florales por A. mellifera, solo algunas resultan atractivas para su cultivo desde el punto de vista agronómico.

\section{Recursos genéticos de interés paisajístico}

Según Naselli (1978), el paisaje es un elenco de imágenes sistematizadas y transmisibles de un sitio, configuradas por pautas culturales propias del tiempo y del lugar, las cuales abarcan el sentido, uso y porqué del entorno, sus características perceptuales, físicas-espaciales y existenciales, además de su significado histórico. Es así como nace la práctica paisajística. Desde sus inicios, el paisajismo se desarrolló como una práctica humana que ha generado ambientes antrópicos que otorgan calidad estética al paisaje a través de la vegetación, mejorando así el entorno ambiental del hombre (Benassi, 2015). Como disciplina de planificación del paisaje, es una actividad emergente. Si bien sus orígenes están en la rama del diseño y de la arquitectura, actualmente sus desafíos son amplios, vinculados con la sustentabilidad, las áreas naturales, la planificación regional, las que trascienden lo meramente ornamental (Burgueño, 2014; Benassi, 2015; Burgueño y Nardini, 2017).
El cultivo de especies nativas en los centros urbanos tiene por función mejorar la calidad de vida de las personas con mínima utilización de insumos y enmiendas, a la vez que reestablecer relaciones biológicas con otros organismos, como insectos y aves. El valor de las especies nativas en paisajismo excede lo estético, siendo sus virtudes la perfecta adaptación a las condiciones edafoclimáticas, las relaciones biológicas que establecen, su valor cultural e histórico e, incluso, su apariencia silvestre, capaz de conectar al ciudadano a lo puramente natural (Carreras et al., 2003; Knapp, 2017).

Argentina se caracteriza por la diversidad y riqueza florística desde el punto de vista paisajístico, la cual ha sido escasamente explorada (Botto y Mata, 2014). Trabajos recientes han contribuido a la obtención de muchas de las variedades ornamentales que se cultivan en el mundo (especies de los géneros Alstroemeria, Begonia, Calceolaria, Calibrachoa, Glandularia, Petunia, Portulaca, entre otros). Existen una cantidad importante de árboles y arbustos nativos que se han cultivado por años en Argentina y en el resto del mundo (especies de los géneros Handroanthus, Jacaranda, Tecoma, Seiba, Tipuana, etc.) (Morisigue et al., 2012; Burgueño y Nardini, 2019).

Considerando que el valor de las especies nativas en paisajismo radica en su perfecta adaptación al ambiente, sus interacciones biológicas y a su aspecto silvestre, resulta difícil seleccionar algunas especies y excluir otras. Si bien muchas son promisorias para ser cultivadas, hemos priorizado aquellas que se destacan por aportar identidad al paisaje, por su valor biológico y por atributos de belleza como floración, follaje, fructificación, perfume, considerando además la factibilidad de obtener semillas u otros pro- 
págulos necesarios para su multiplicación (Pensiero y de la Peña, 1999; Demaio et al., 2002; Hurrell y Lahitte, 2003; Hurrell et al., 2004; Haene, 2007; Haene y Aparicio, 2009; de la Peña y Pensiero, 2017; Menini y Burgeño, 2018).

\section{MATERIALES Y MÉTODOS}

Sobre la base de lo citado para la flora de la provincia de Santa Fe por Pensiero et al. (2005), Zuloaga et al. (2019), por el portal de Flora Argentina (ww.floraargentina.edu. ar) y del estudio de las colecciones depositadas en el Herbario "Arturo E. Ragonese" (SF), se seleccionaron aquellas especies que, según nuestro criterio, son consideradas recursos fitogenéticos prioritarios. La nomenclatura de las especies tratadas sigue, en términos generales, a Zuloaga et al. (2019) y al portal de Flora Argentina (www.floraargentina.edu.ar).

En las especies de interés forestal se incluyó información del valor forrajero de sus frutos. En las especies herbáceas de interés forrajero se incorporó información de su hábito de crecimiento y ciclo productivo. En las especies de interés apícola se brinda información sobre forma de vida, recursos que brindan y meses de floración. En las especies de interés paisajístico se brinda información de la forma de vida y uso en el paisaje.

En todas las especies se analiza su distribución geográfica según los departamentos provinciales en los que ha sido colectada, con la finalidad de determinar áreas prioritarias para iniciar planes de conservación (ex situ e in situ). Además, se presenta información sobre la capacidad de conservación de sus semillas, indicándose en particular su condición de ortodoxa, intermedia o recalcitrante. A nivel biológico, la humedad míni- ma que toleran las semillas varía de forma cuantitativa en un amplio rango de valores, de $60 \%$ a menos de 5\%, aproximadamente (Hong y Ellis, 1996). A nivel práctico, en la mayoría de los Bancos de Germoplasma se catalogan como especies ortodoxas aquellas cuya semilla se puede conservar por largo tiempo en condiciones de humedad menores a 5\%. Las especies con semillas intermedias, pueden conservarse en condiciones de humedad entre 5\% y $10-12 \%$. Las especies recalcitrantes poseen semillas que pierden la viabilidad en condiciones de humedad menores al 10-12\%, y su conservación ex situ se realiza por otros medios, por ejemplo, jardines de plantas vivas. Por último, se indican las especies que son conservadas en el Banco de Germoplasma “Ing. Agr. José Mario Alonso”, el número de entradas conservadas y entradas conservadas en otros bancos de germoplasma.

Quedaron fuera de este análisis tres categorías de recursos fitogenéticos de especies silvestres, las especies para alimentación humana, las de uso industrial y medicinal (Khoury et al., 2019). Dada la cantidad de especies en estas categorías, es necesario abordarlas en otra publicación.

\section{RESULTADOS Y DISCUSIÓN}

\section{Recursos genéticos forestales}

Se presentan 24 especies nativas de interés forestal consideradas prioritarias para introducir a cultivo (Tabla 1). La mayoría de estas especies tienen interés, además, por representar en nuestra provincia los ejemplares más australes de su distribución geográfica. Presentan particular interés Prosopis hassleri var. nigroides y P. nigra var. ragonesei, por ser endémicas de Santa Fe (es decir, crecen únicamente en esta provincia). 
Por otro lado, 11 de las 24 especies listadas poseen frutos que son considerados recursos forrajeros, algunos de los cuales se consideran estratégicos, ya que están disponibles en períodos de escasez de forraje como ocurre con los frutos de de guayacán (Libidibia paraguariensis), en invierno.

Recursos genéticos de interés forrajero La provincia de Santa Fe es particularmente rica en especies nativas forrajeras, por lo que se han priorizado 45 especies herbáceas (17 leguminosas y 28 gramíneas), de las cuales solo dos son de ciclos anuales y las restantes perennes (Tabla 2). La mayoría de estas especies son de crecimiento primavera-estivo-otoñal. Solamente 6 especies poseen crecimiento otoño-inverno-primaveral, y deben considerarse especialmente debido a que producen forraje en época donde resulta escasa la oferta por los pastizales. Dieciséis especies fueron citadas por Pensiero y Zabala (2017) como tolerantes a la salinidad y/o inundación, constituyendo un recurso de interés particular, ya que se adaptan a una amplia región ganadera de la provincia como son los Bajos Submeridionales. La mayoría de las especies priorizadas podrían ser útiles en gran parte de la región ganadera del centro-norte de Argentina. En tal sentido, en el marco del PRODOCOVA se han realizado numerosos viajes de relevamiento y colecta de germoplasma de estas especies en distintas provincias de Argentina, conformando en la actualidad una colección única de su tipo en el país, conservada en el Banco de Germoplasma "Ing. Agr. José M. Alonso". Con algunas de estas especies se ha realizado un programa de mejora genética, fruto del cual se han inscripto varios cultivares ante el INASE, y algunos de ellos han sido licenciados para su comercialización bajo convenios de vinculación tecnológica con empresas semilleras (Pensiero et al., 2017).

\section{Recursos genéticos de interés apícola}

En la flora santafesina existen 32 especies que, a nuestro criterio, pueden ser cultivadas para incrementar la oferta de recursos para la producción de miel (Tabla 3). En este trabajo, el proceso de priorización de especies con potencial apícola de la flora santafesina se realizó en base a los siguientes caracteres: 'polen, néctar y/o sustancias resinosas como recompensa floral', 'períodos de floración', 'alta intensidad de visitas de forrajeo', ‘floración abundante y/o extensa', ‘ausencia de toxicidad para animales', 'hábito de vida no invasivo’ y ‘posibilidad de utilizarlas con doble propósito’. El período de floración y tipo de recompensa floral ofrecida fueron rasgos relevantes en la priorización de especies, ya que se encuentran en estrecha relación con la dinámica de la colmena.

Muchas de ellas también son fuente de recursos para abejas nativas 'sin aguijón' (Flores y Sánchez, 2010; Vossler, 2015) y otros taxones de la entomofauna local (Aizen y Feisinger 1994; Dalmazzo 2010; Dalmazzo y Vossler 2015; Cerino et al. 2015; Cerino et al. 2018; Cuffia, 2019). Diez especies son de particular importancia ya que florecen en los meses de otoño e invierno, cuando la oferta floral natural es escasa a nula. El aporte de recursos de estas especies es destacable ya que en dicho período transcurre la etapa más crítica de la temporada apícola, la invernada (Somerville, 2010). Durante la misma, se han registrado las mayores mortandades de abejas a nivel mundial y la falta de alimento fue mencionada como la principal causa (Naug, 2009; Steinhauer et al., 2014). Fue demostrado que el aporte realizado mediante cultivos melíferos poliflorales, en el período pre-invernal, mejora significativamente la fisiología de las abejas (específicamente, cuerpo graso y nivel de vitelogenina) (Alaux et al., 2017). 
Recursos fitogenéticos de Santa Fe (Argentina)

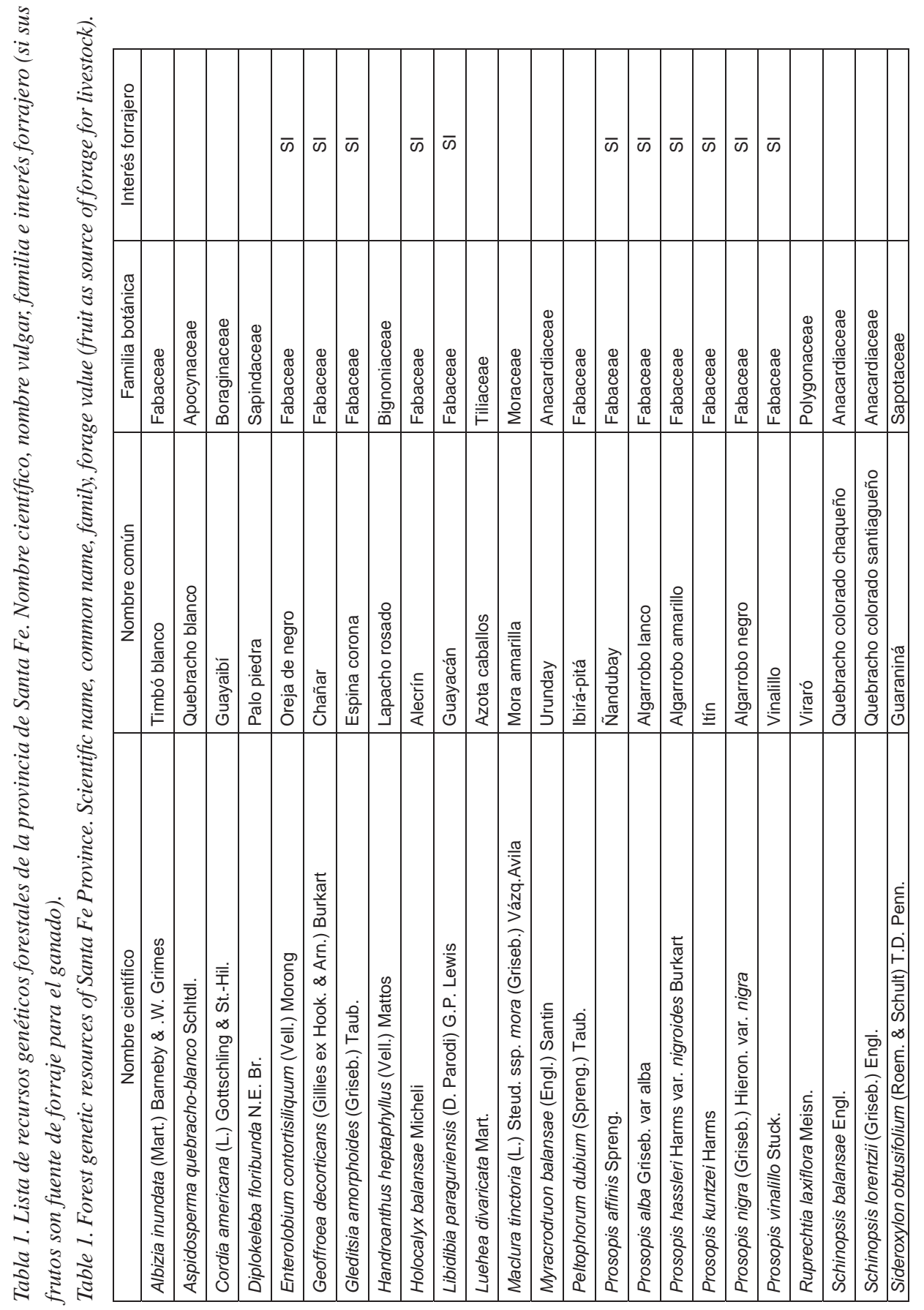

Revista FAVE - Ciencias Agrarias 20 (1) 2021 | 


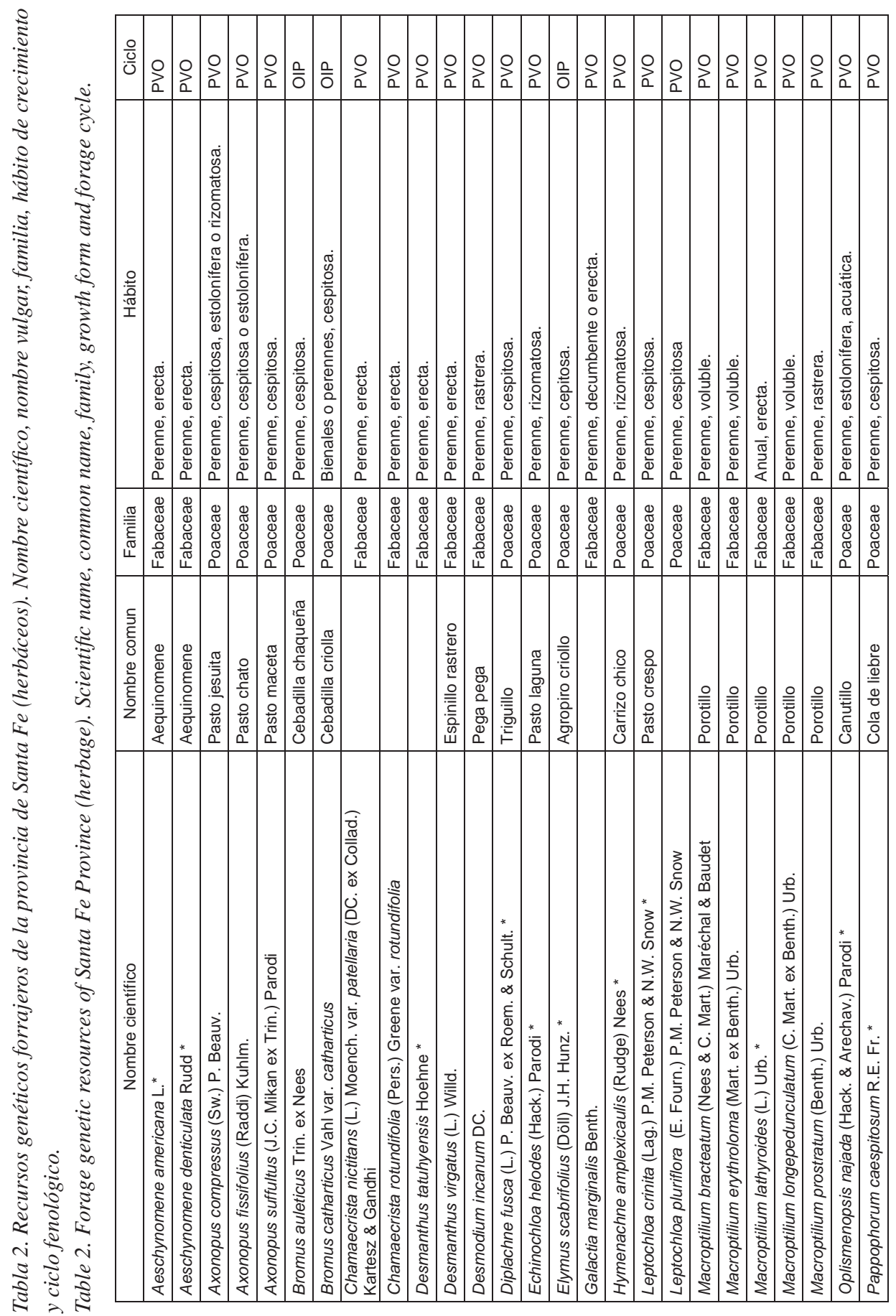




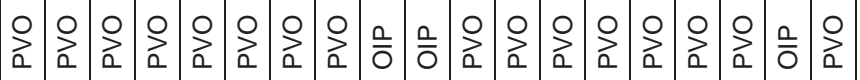
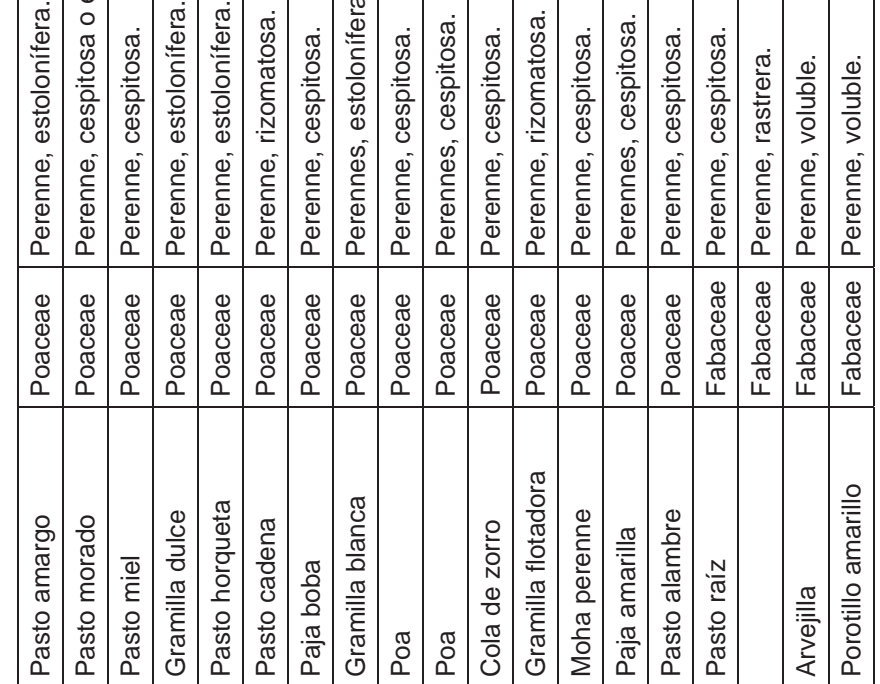

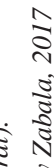

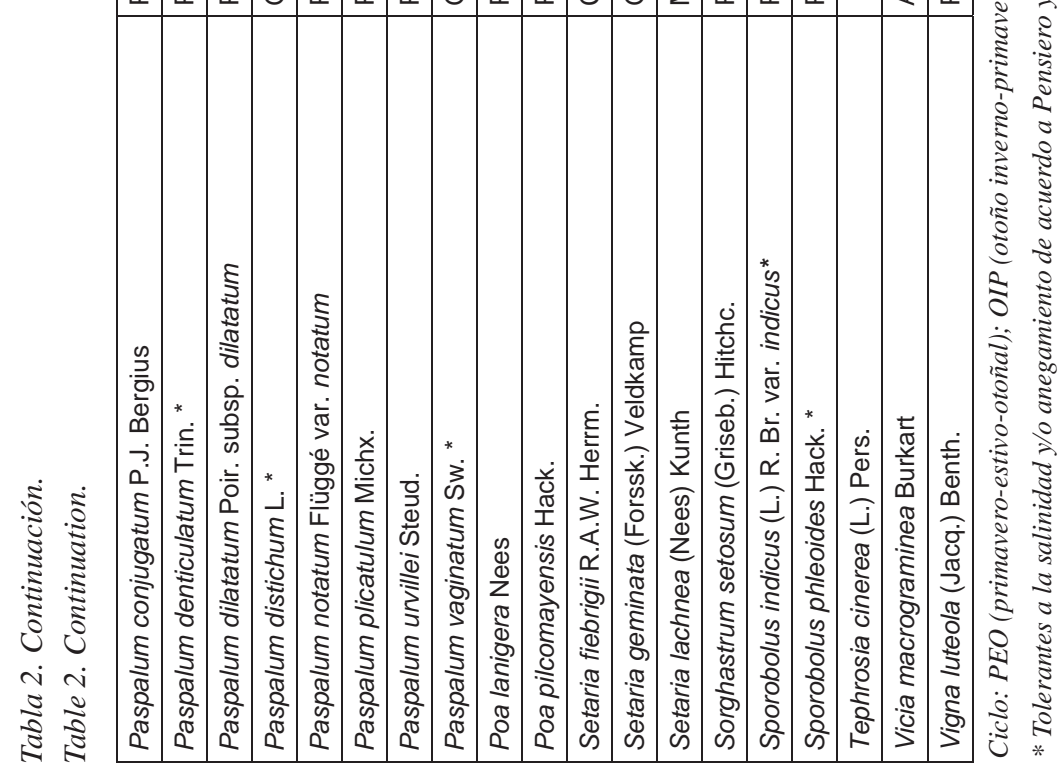

Revista FAVE - Ciencias Agrarias 20 (1) 2021 | 


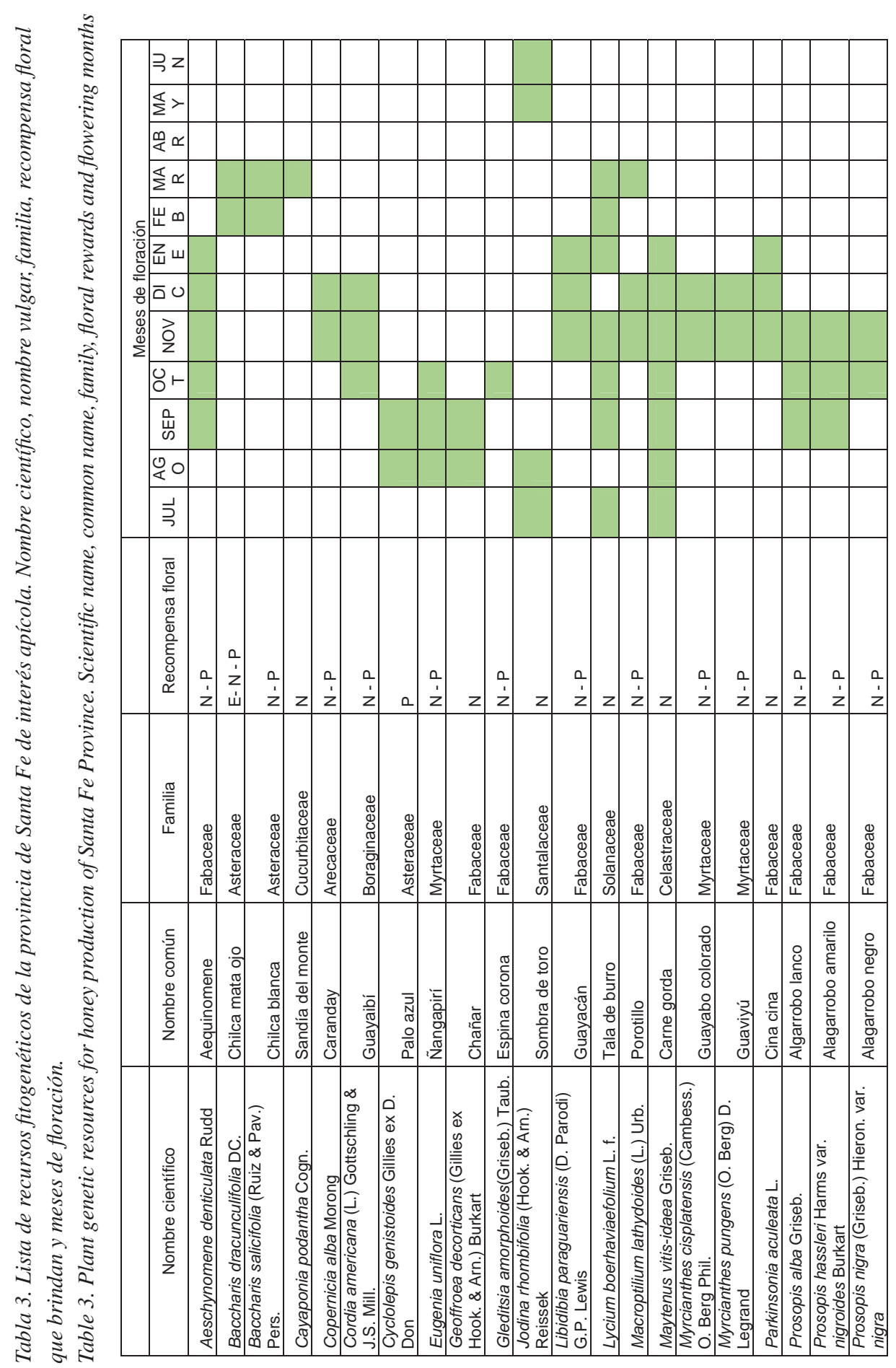




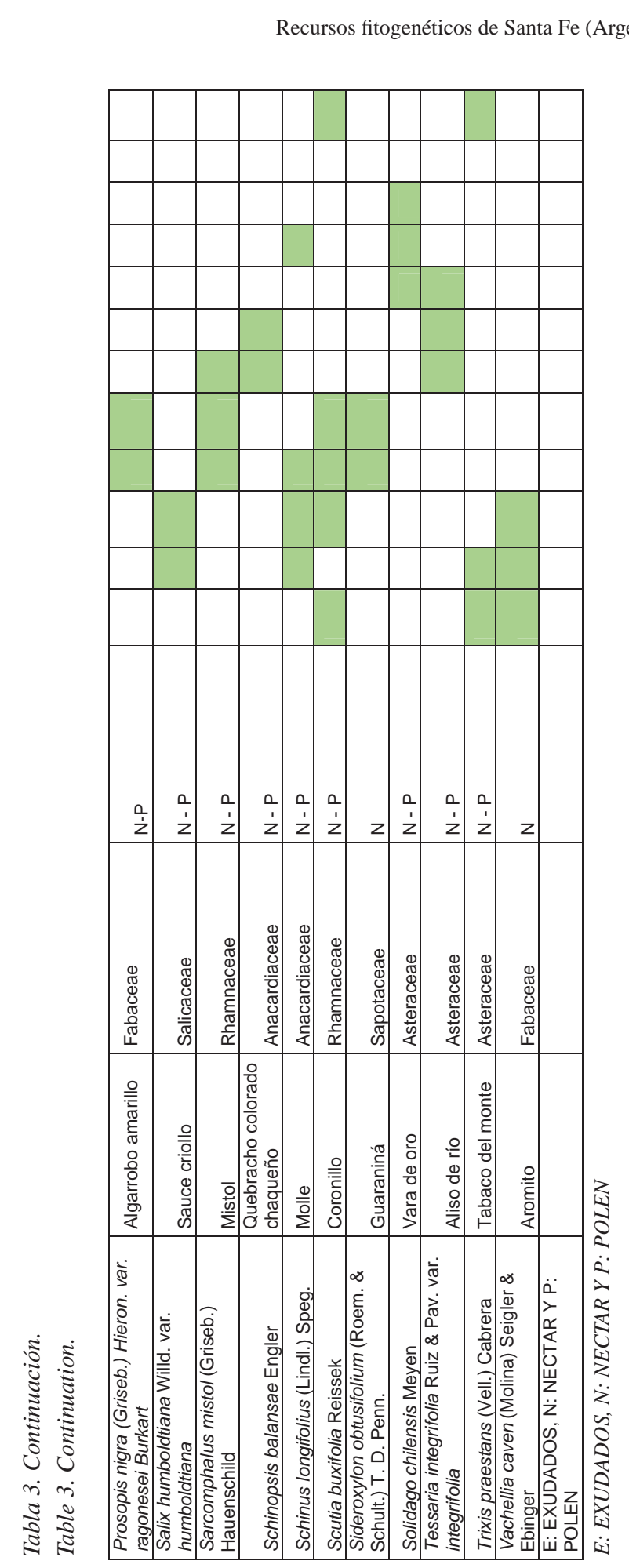

Revista FAVE - Ciencias Agrarias 20 (1) 2021 | 
En primavera son importantes en el aporte de polen y néctar para sostener la postura y el nacimiento de obreras que pasarán el invierno, y la acumulación de reservas para la invernada. Cyclolepis genistoides es una fuente importante de polen (Tamame, 2011) al inicio de la temporada apícola (agosto); período que requiere, principalmente, fuentes de polen para alimentar castas inmaduras e incrementar el número de individuos. Eugenia uniflora, Geoffroea decorticans y Schinus longifolius proveen abundante polen y néctar a inicio de la temporada y en primavera (Cabrera et al., 2013; Fagúndez et al., 2016), recursos muy importantes para sostener la población y la actividad de las pecoreadoras. Gleditsia amorphoides es un interesante recurso que aporta abundante polen y néctar en una floración concentrada en el mes de octubre (Cerino et al., 2018).

En el verano, las fuentes de néctar se utilizan para mantener una alta cantidad de individuos en las colmenas y almacenar las reservas para el periodo desfavorable. En este período son importantes los aportes de Myrcianthes cisplatensis, Myrcianthes pungens (Cabrera et al., 2013; Fagúndez et al., 2016), Parkinsonia aculeata (Fagúndez et al., 2016) y Schinopsis balansae (Cabrera et al., 2013). En relación a los recursos ofrecidos, 18 especies proveen recursos polen-nectaríferos. Sólo Baccharis dracunculifolia fue mencionada como fuente de polen, néctar y resinas (Weinstein Teixeira et al., 2005). Trabajos que indiquen el origen de secreciones o exudados resinosos para la producción de propóleos son escasos (Weinstein Teixeira et al., 2005; Sawaya et al., 2006). Estudios realizados en nuestro país, en general describen la flora nativa típica de las regiones de producción de propóleos, pero no sugieren el origen botánico (Tosi et al., 2006; Maldonado et al., 2018). Por lo tanto, se dificulta hallar referencias bibliográficas sobre especies vegetales que aporten materia prima para la elaboración de propóleos.

\section{Recursos genéticos de interés paisajístico}

Se seleccionaron 69 especies en relación a diferentes atributos de interés paisajístico (Tabla 4). De estas especies, 29 son árboles, 18 arbustos y subarbustos, 9 enredaderas y 13 especies herbáceas. Para los árboles se priorizaron diferentes magnitudes, texturas, densidades y persistencia del follaje, presencia de frutos carnosos o secos, atendiendo a las necesidades del diseño paisajista. A modo de ejemplo, se indican especies de follaje persistente como Myrsine laetevirens, Myrcianthes cisplatensis, Nectandra angustifolia, y especies de follaje caduco como Sapindus saponaria, Vachellia aroma, Sideroxylon obtusifolium; especies de frutos carnosos como Tabernaemontana catharinensis, Acanthosyris falcata, Crateva tapia y frutos secos como Ruprechtia laxiflora, Cordia americana y Croton urucurana. La floración profusa y la presencia de perfumes, tienen alta relevancia y se relacionan con el valor biológico, por la atracción de polinizadores y aves (Tabebuia nodosa, Vachellia caven, Tabernaemontana catharinensis y Luehea divaricata).

En el caso de los arbustos de gran porte, la presencia de espinas se consideró de valor para la realización de cercos vivos, a la vez que estas especies favorecen la nidificación y proveen frutos carnosos que son un recurso alimenticio para aves (de la Peña y Pensiero, 2017) y fauna asociada (Celtis pallida var. pallida, Schinus longifolius var. longifolius, Scutia buxifolia). 
Recursos fitogenéticos de Santa Fe (Argentina)

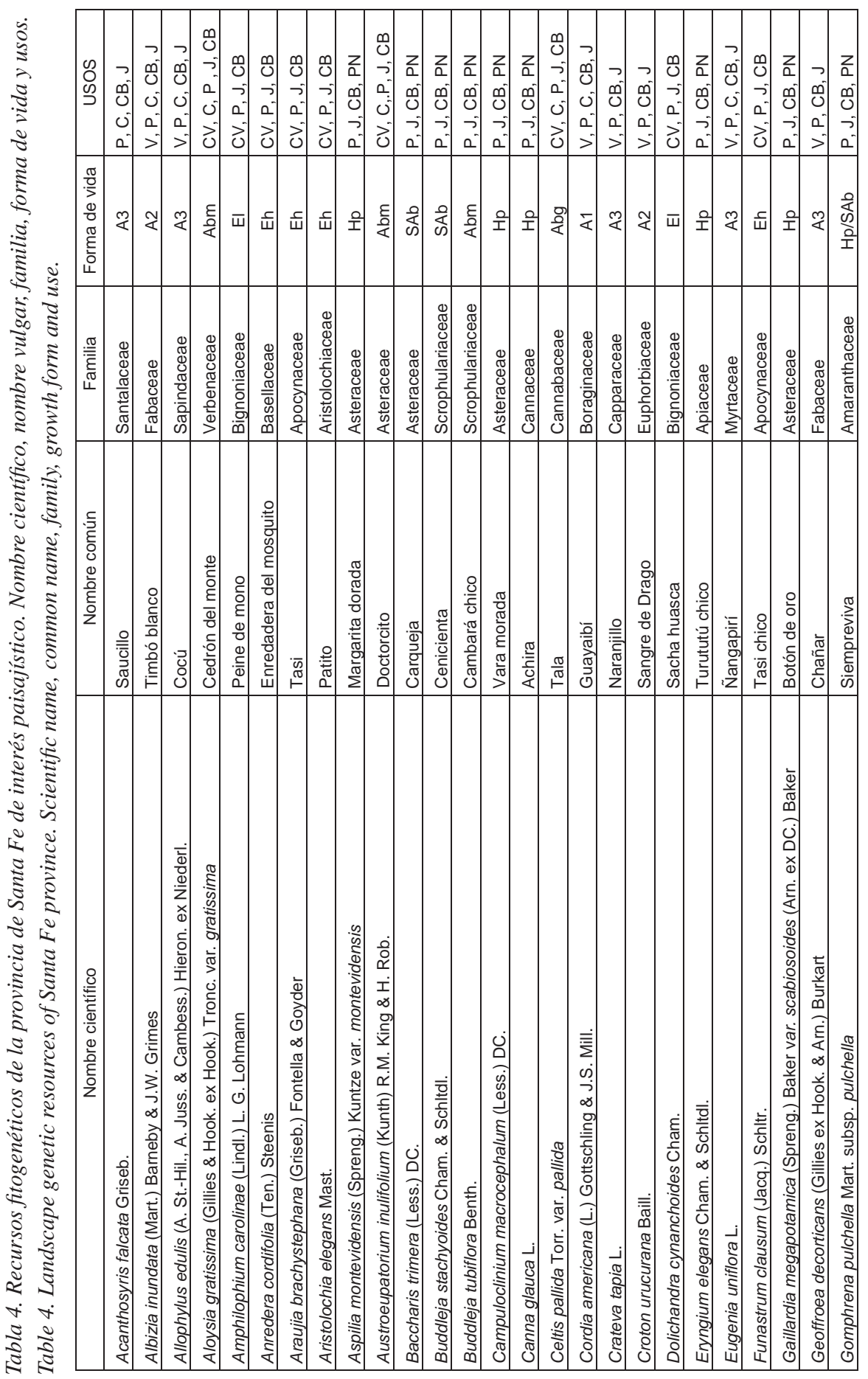

Revista FAVE - Ciencias Agrarias 20 (1) 2021 | 


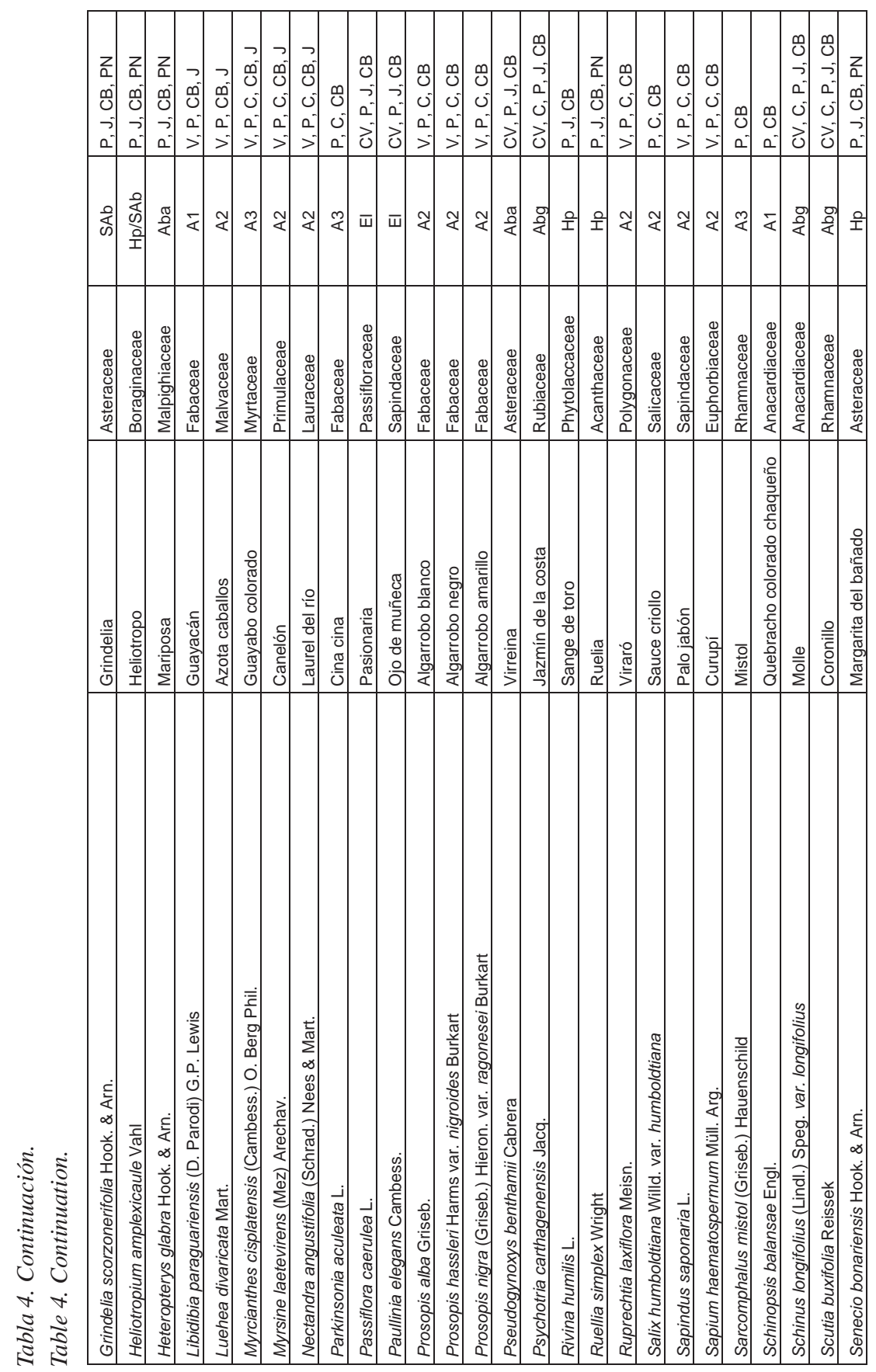


Recursos fitogenéticos de Santa Fe (Argentina)

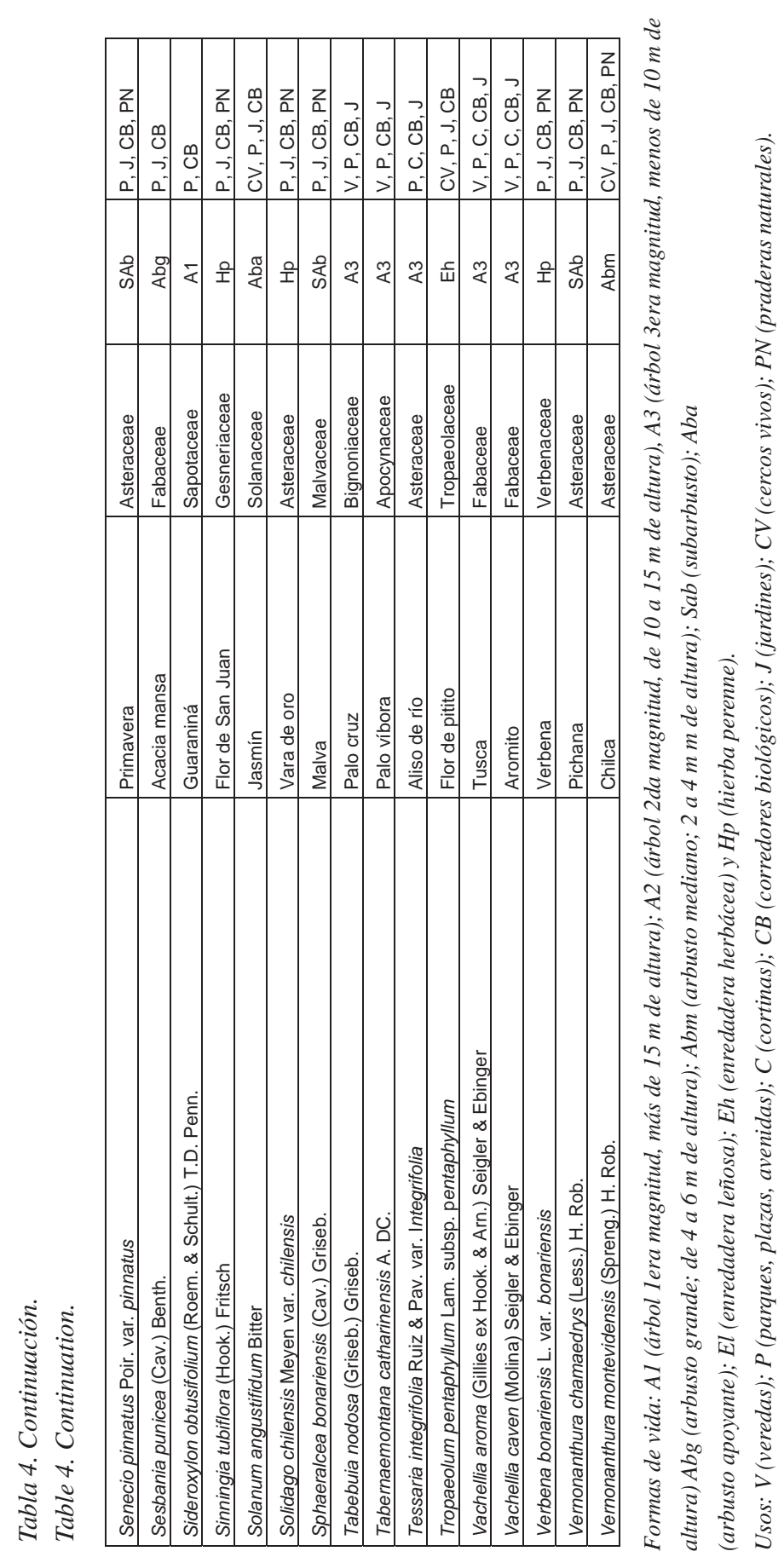

Revista FAVE - Ciencias Agrarias 20 (1) 2021 | 
Si se realiza una descripción exhaustiva de las especies señaladas como promisorias, la mayor parte de ellas satisfacen varios de los criterios de selección empleados. Así, por ejemplo, especies como Geoffroea decorticans, Eugenia uniflora, Allophylus edulis, Sarcomphalus mistol, son árboles de reducidas dimensiones (3era magnitud) muy útiles en determinadas situaciones de cultivo donde la altura es limitante, poseen alto valor biológico tanto por la atracción de polinizadores durante la floración, como por la atracción de aves y fauna debido a la presencia de frutos carnosos. Además, estos frutos también se pueden utilizar en alimentación humana.

En el caso de arbustos menores, subarbustos y hierbas perennes, se priorizó la floración y presencia de perfumes y su consiguiente valor como elemento determinante de biodiversidad, por la atracción de mariposas, abejas y otros polinizadores (Austroeupatorium inulifolium, Aloysia gratissima var. gratissima, Baccharis trimera, Campuloclinium macrocephalum, Solidago chilensis). Entre las especies señaladas existe diversidad en atributos paisajísticos como ser altura, color y persistencia del follaje, color de flores y época de floración.

Las enredaderas seleccionadas presentan flores llamativas o muy perfumadas, frutos vistosos o alimenticios para aves, se relacionan con picaflores, mariposas e incluso resultan nutricias para algunas de ellas, lo que implica que sus orugas sólo pueden alimentarse de estas plantas. Otra vez, los atributos de las especies seleccionadas son múltiples, por ejemplo, Passiflora caerulea tiene flores de singular belleza que además atraen polinizadores, principalmente abejorros, sus frutos carnosos son alimento para muchas aves, como calandria, zorzal, celestino y otros animales, además, es planta nutricia de la mariposa espejitos (Agraulis vanillae). Las especies de Apocináceas seleccionadas (Araujia brachystephana y Funastrum clausum) poseen flores muy curiosas, intenso perfume y son nutricias de la mariposa monarca (Danaus sp.), a la vez que sus frutos tienen aplicaciones como alimenticios.

En cuanto a usos se definieron las diferentes situaciones de diseño y cultivo donde las especies pueden utilizarse, atendiendo a sus dimensiones y forma de vida, en ámbitos de carácter público y privado. Por ejemplo, en la actualidad se fomenta el uso de corredores biológicos al costado de rutas y caminos, por lo cual ese uso está incluido en este trabajo.

\section{Aspectos generales de la distribución y conservación de los recursos fitogenéticos de la provincia de Santa Fe}

En relación al uso de las especies, 29 de las 138 especies listadas tienen más de una utilidad. Estas especies deberían considerarse prioritarias en estudios básicos y en el desarrollo de programas de introducción a cultivo en la provincia de Santa Fe. Siete de ellas tienen interés forestal, paisajístico y apícola: Geoffroea decorticans, Libidibia paraguariensis, Prosopis alba, Prosopis hassleri var. nigroides, Cordia americana, Schinopsis balansae y Sideroxylon obtusifolium. Las cuatro primeras además son útiles desde el punto de vista de la producción de frutos forrajeros. Prosopis alba además tiene interés alimenticio, uso no abordado en este trabajo. Gleditsia amorphoides, Prosopis nigra var. nigra, Prosopis affinis, Prosopis kuntzei y Prosopis vinalillo pueden ser utilizadas como recursos forestales, de interés apícola, y sus frutos también son considerados forrajeros. Doce especies son consideradas de interés paisajístico y apí- 
cola (Eugenia uniflora, Myrcianthes cisplatensis, Parkinsonia aculeata, Prosopis nigra var. ragonesei, Albizia inundata, Salix humboldtiana, Tessaria integrifolia, Sarcomphalus mistol, Schinus longifolius, Scutia buxifolia, Solidago chilensis, Vachellia caven y Vachellia aroma). Dos especies son de interés forrajero y apícola (Aeschynomene denticulata y Macroptilium lathyroides). Tres especies tienen interés forestal y paisajístico (Albizia inundata, Luehea divaricata y Ruprechtia laxiflora).

Los 138 recursos fitogenéticos priorizados crecen en 18 de los 19 departamentos de la provincia (Tabla 5; Figura 1a). Los departamentos del norte de la provincia son los más ricos en presencia de especies debido a los distintos tipos de vegetación que presentan y, posiblemente, a una menor antropización que los departamentos del centro-sur. Las 30 especies que crecen en menos de 2 departamentos (Figura 1b) se encuentran en los departamentos del norte provincial. El 84,1 \% (116) y 70,3\% (97) de las especies seleccionadas crecen en los departamentos General Obligado y Vera respectivamente. En estos dos departamentos se halla el 94,2\% (130) de las especies relevadas. Por otro lado, en los departamentos 9 de Julio, San Cristóbal y San Javier crece aproximadamente el $50 \%$ de las especies relevadas. Las especies que crecen en los Departamentos del Norte de Santa Fe pueden realizar un aporte significativo al incremento de la producción de carne y miel, como así al desarrollo de una producción forestal a partir de especies nativas.

Para la determinación del tipo de semilla en relación a la capacidad de conservación ex situ se utilizó como principales fuentes de datos la información de la base de datos del Jardín Botánico de Kew (Kew Royal Botanic Gardens, 2020) y el libro sobre especies de árboles de la Cuña Boscosa (Alzugaray y Carnevale, 2009). Para algunas especies la bibliografía es escasa y se encontraron solo una cita de su comportamiento como en Maclura tinctorea (Carvalho et al., 2003), Luehea divaricata (Medeiros y Eira, 2006), Passiflora coerulea (Miranda et al., 2009) y Tabernaemontana catharinensis (Afonso, 2016). Ochenta y seis especies son ortodoxas, 4 recalcitrantes y para 48 especies no hay antecedentes publicados sobre la tolerancia de las semillas a la desecación. La mayoría de las especies sin datos pertenecen a familias o géneros donde más del 95\% de las semillas de sus especies son consideradas ortodoxas. Algunos ejemplos de éstas últimas son Lycium boerhaviaefolium (28 especies del género con semillas ortodoxas) o Baccharis dracunculifolia (31 especies del género con semillas ortodoxas). Por otro lado, muchas de las especies sin datos pertenecen a la familia Asteraceae, en la cual el 97,9\% de las especies con comportamiento conocido son ortodoxas. Las únicas especies sin datos y/o con comportamiento dudoso en las que deberían llevarse a cabo estudios sobre tolerancia a la desecación de sus semillas son Salix humboldtiana, Sapindus saponaria, Tabebuia nodosa, Jodina rhombifolia y Acanthosyris falcata. En Salix humboldtiana no existen antecedentes publicados y en el $17 \%$ de las especies de la que se posee información, sus semillas son recalcitrantes. De acuerdo a Salomao et al. (2005), Sapindus saponaria posee semillas de comportamiento ortodoxo, sin embargo, Sautu et al. (2006) y la base de datos de Kew (Kew Royal Botanic Gardens, 2020) la citan como de comportamiento dudoso. Tabebuia nodosa posee semillas ortodoxas de acuerdo a Kew (Kew Royal Botanic Gardens, 2020) y a Abraham de Noir (1991). Sin embargo, 
Alzugaray y Carnevale (2009) indican que las semillas de esta especie pierden viabilidad luego de un año cuando son secadas a 6-7\% HR y conservadas a baja temperatura. Por último, para Jodina rhombifolia y Acanthosyris falcata no existe información sobre el comportamiento de las semillas. De las 6 especies de la familia Santalaceae a la que pertenecen ambas especies y en la que existe información, 3 especies poseen semillas recalcitrantes. Para estas dos especies Alzugaray y Carnevale (2009) reportan que no hay podido hacer germinar semillas luego de varios tratamientos como escarificación, por lo que habría dormición fisiológica en sus semillas.
En el Banco de Germoplasma “Ing. Agr. José Mario Alonso" de la FCA-UNL se conservan 376 entradas de 44 especies de las priorizadas en este trabajo (Tabla 5), lo que representa una colección de germoplasma del 32\% de las especies relevadas. En relación a la existencia de colecciones de estas especies en otros Bancos de Germoplasma, se consultó la información disponible en la base de datos Genesys (https:// www.genesys-pgr.org/), la cual contiene información de los Bancos de Germoplasma más importantes del mundo. En esta base de datos se reportan 6.293 entradas de 73 especies $(52,8 \%)$ relevadas, que se conservan en diversos países, principalmente Estados Unidos, Australia y Brasil.
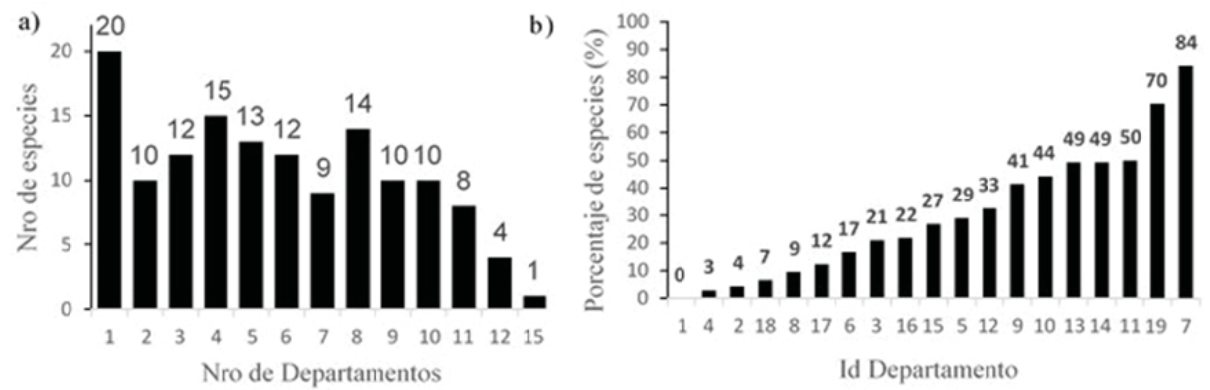

Figura 1. Número de especies por Departamento de la Provincia de Santa Fe (a) y distribución de especies por Departamento (b). Id Departamento: Belgrano (1), Caseros (2), Castellanos (3), Constitución (4), Garay (5), General López (6), General Obligado (7), Iriondo (8), La Capital (9), Las Colonias (10), 9 de Julio (11), Rosario (12), San Cristóbal (13), San Javier (14), San Jerónimo (15), San Justo (16), San Loreno (17), San Martín (18) y Vera (19).

Figure 1. Number of species in different Santa Fe Departments (a) and species distribution by Department (b). Id Departments Belgrano (1), Caseros (2), Castellanos (3), Constitución (4), Garay (5), General López (6), General Obligado (7), Iriondo (8), La Capital (9), Las Colonias (10), 9 de Julio (11), Rosario (12), San Cristóbal (13), San Javier (14), San Jerónimo (15), San Justo (16), San Loreno (17), San Martín (18) and Vera (19). 
Recursos fitogenéticos de Santa Fe (Argentina)

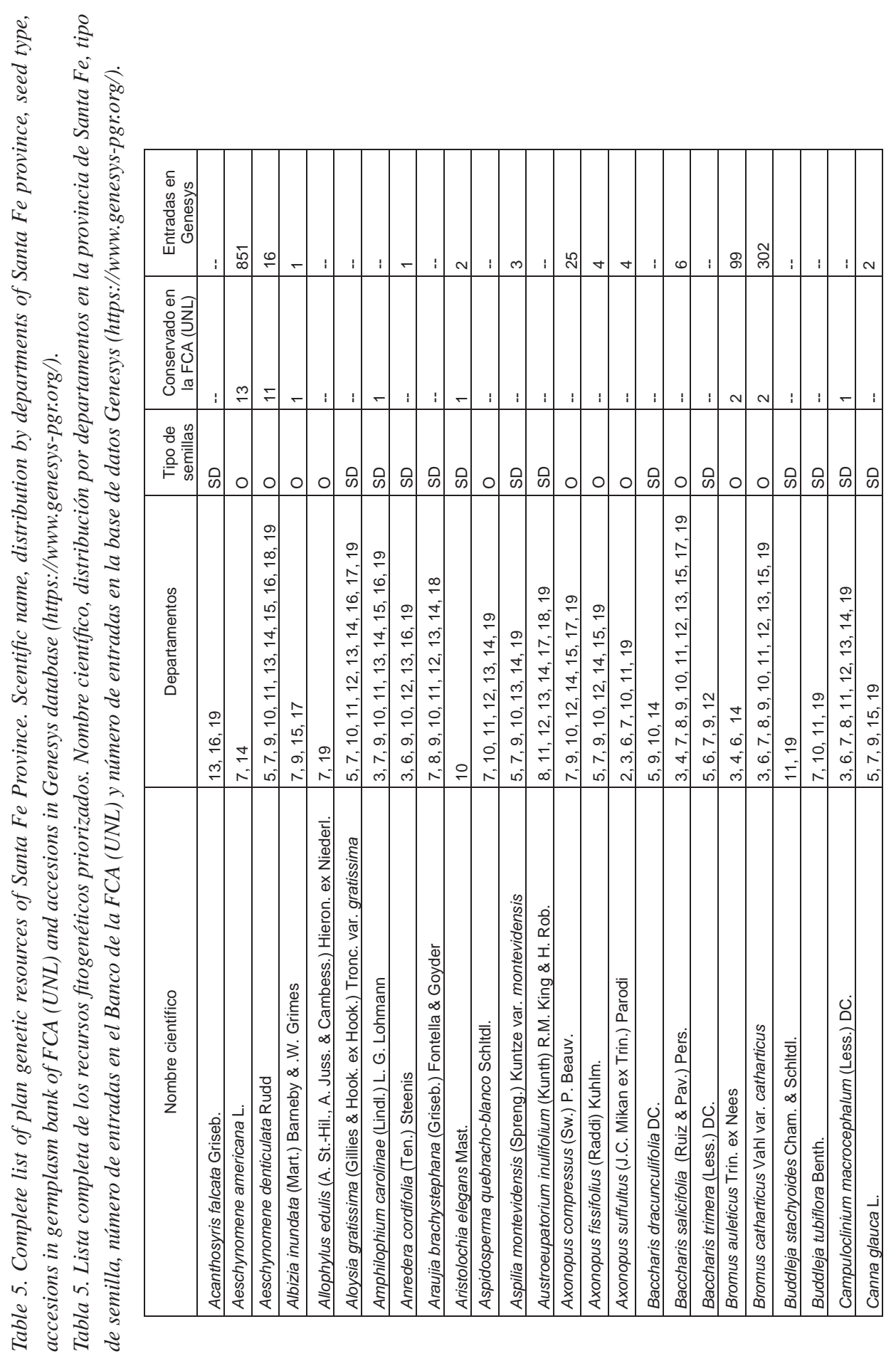

Revista FAVE - Ciencias Agrarias 20 (1) 2021 | 


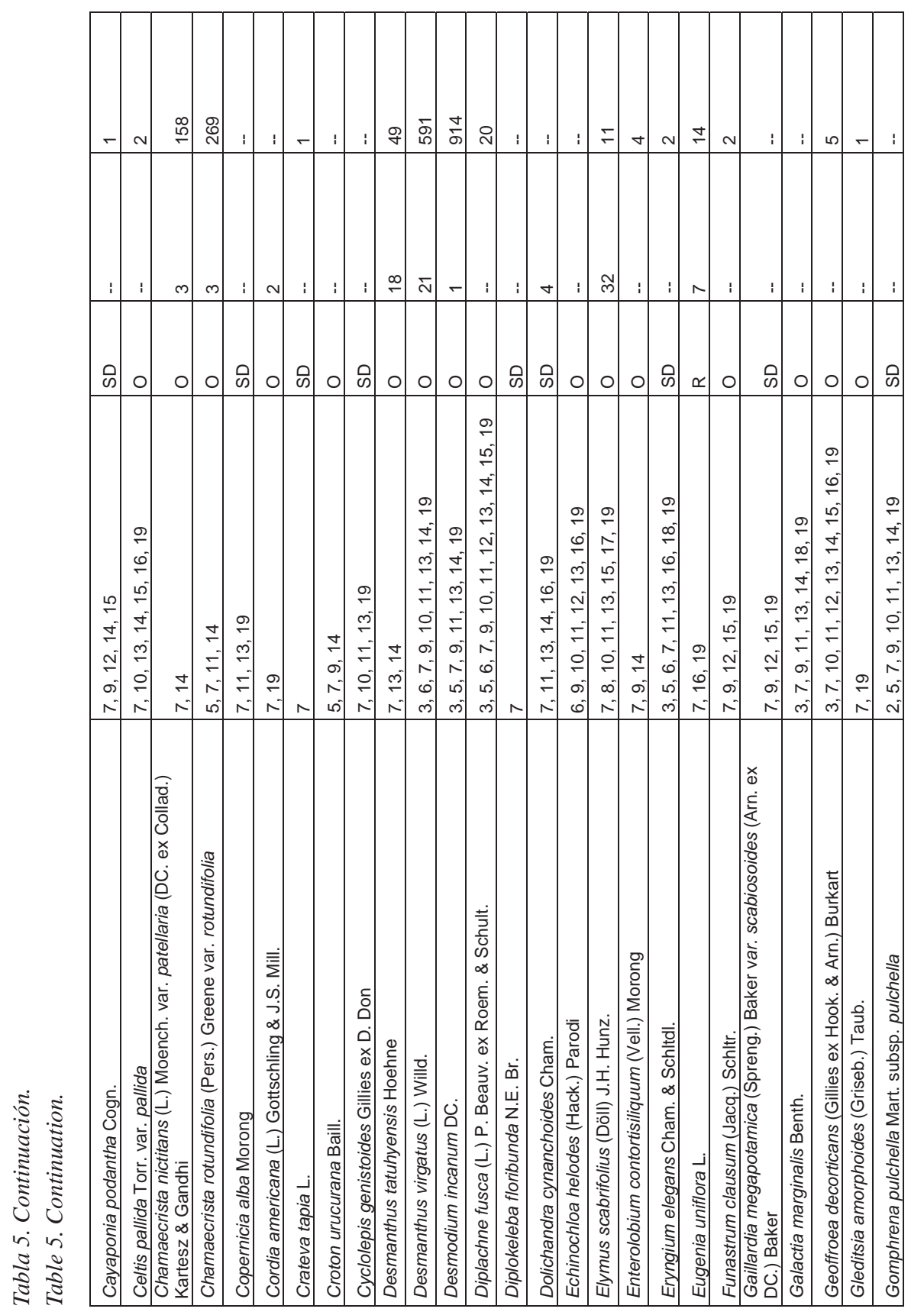


Recursos fitogenéticos de Santa Fe (Argentina)

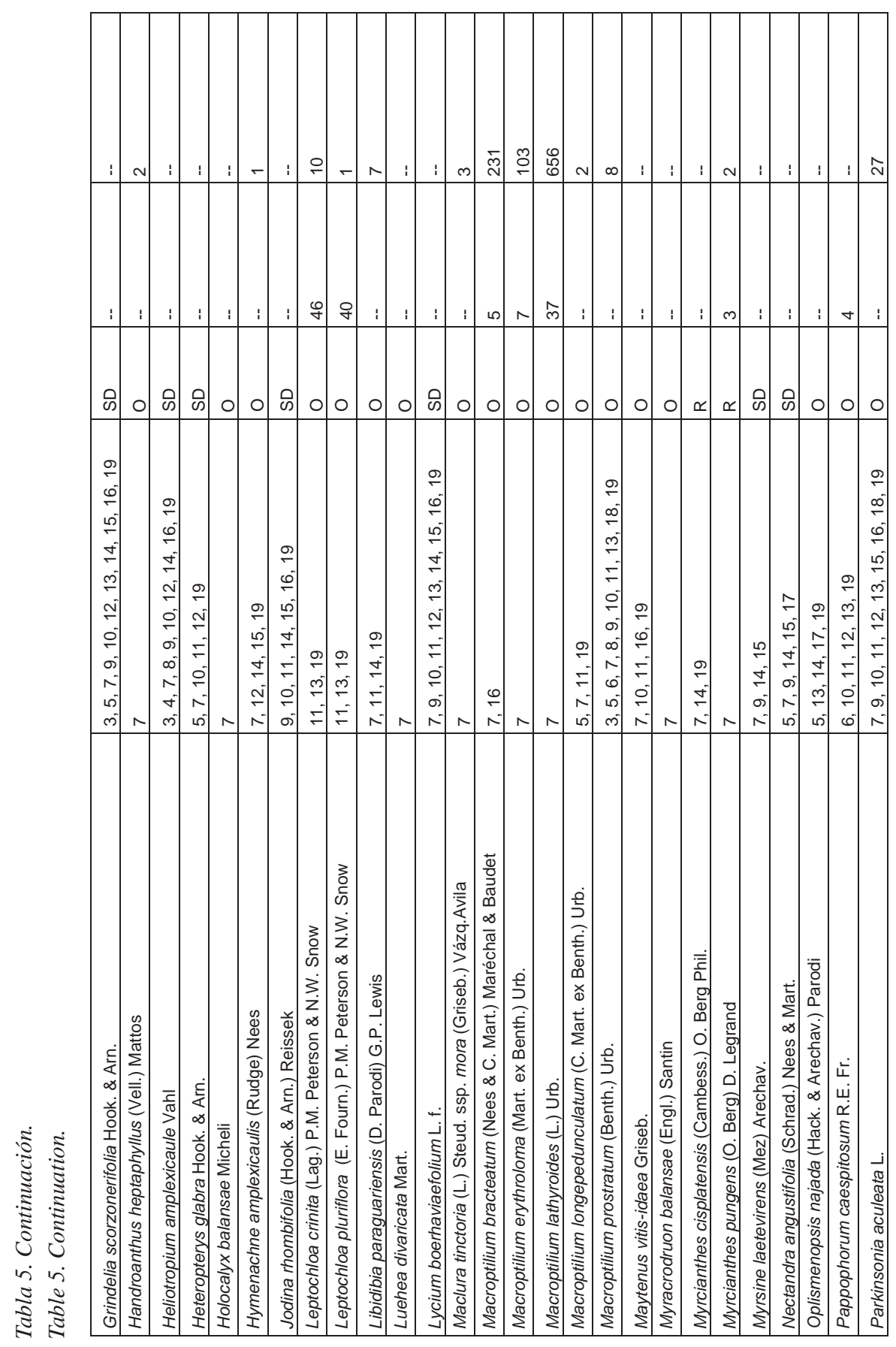

Revista FAVE - Ciencias Agrarias 20 (1) 2021 | 


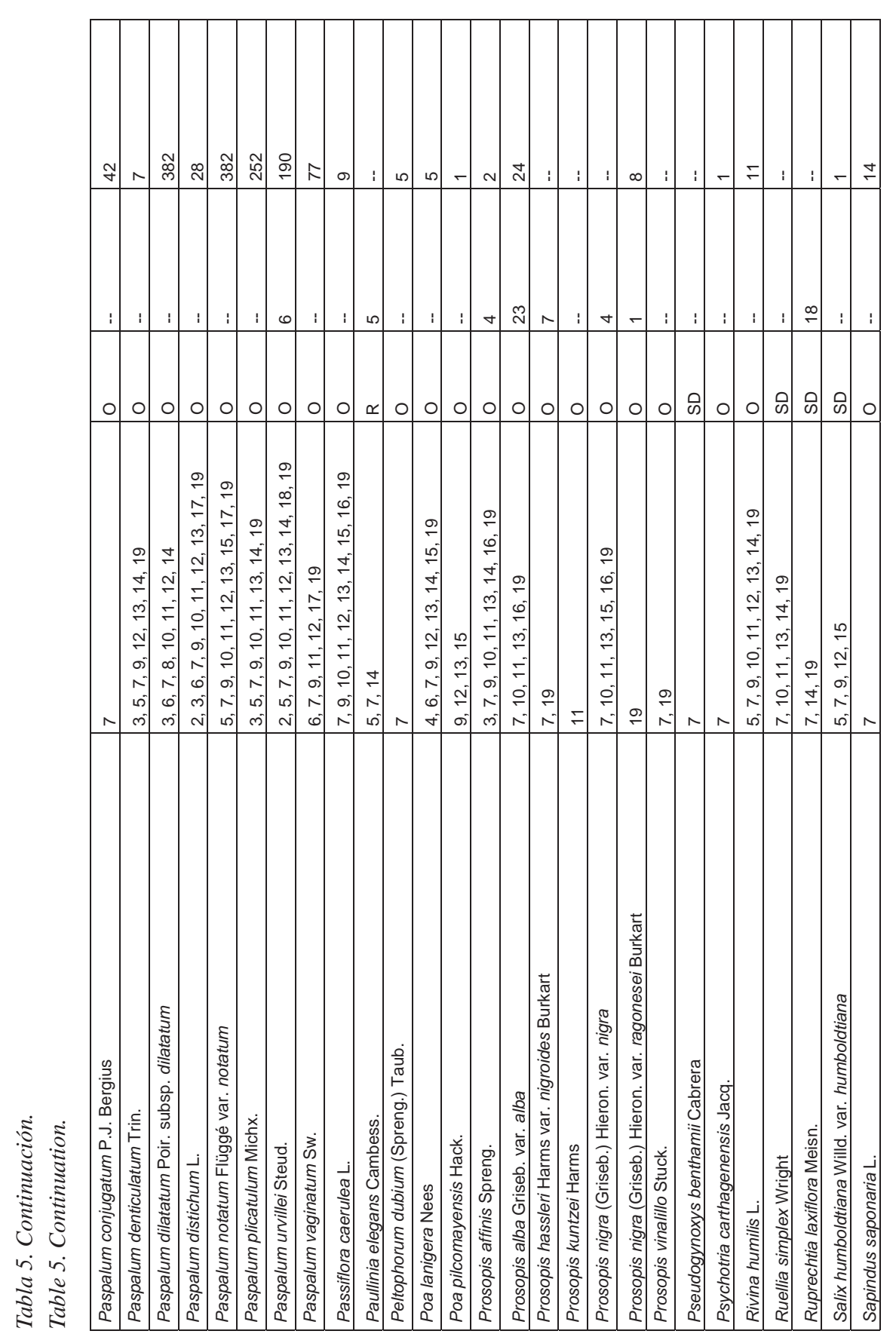


Recursos fitogenéticos de Santa Fe (Argentina)

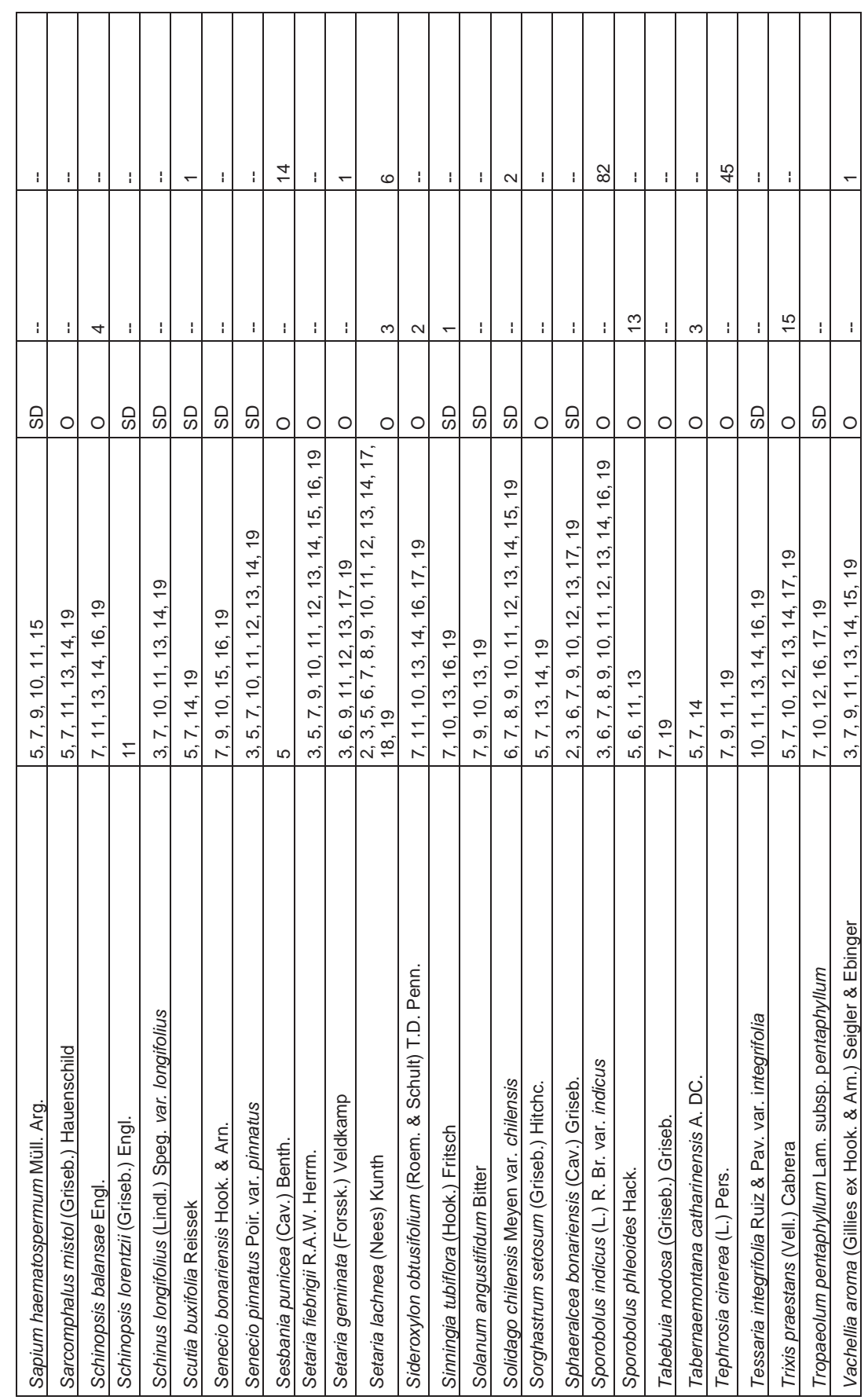

Revista FAVE - Ciencias Agrarias 20 (1) 2021 | 


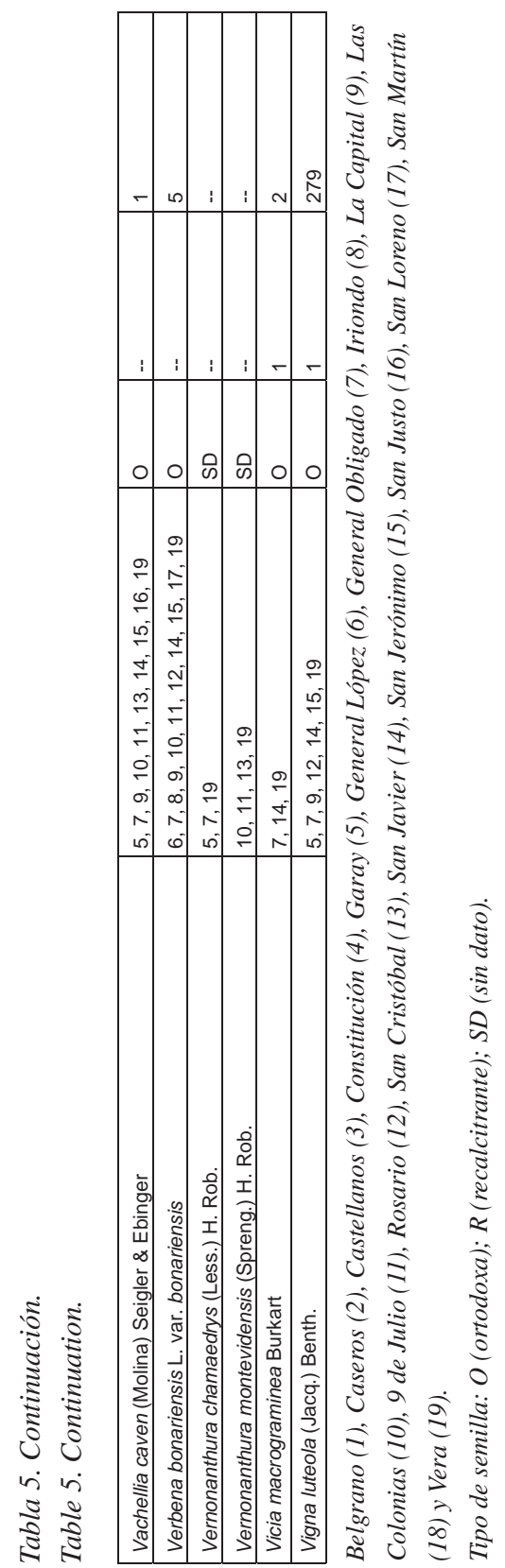




\section{CONCLUSIONES}

La provincia de Santa Fe contiene un número significativo de recursos fitogenéticos de interés forestal, forrajero, apícola y paisajístico. La priorización y estudio de las especies en el PRODOCOVA es fruto de trabajos básicos y el desarrollo de tecnología de manera interdisciplinaria, cuyos pilares son dos colecciones biológicas de suma importancia, el Herbario "A. Ragonese” y el Banco de Germoplasma "Ing. Agr. José Mario Alonso".

La importancia de las especies priorizadas se evidencia en la presencia de gran cantidad de entradas conservadas en diferentes Bancos de Germoplasma del mundo. Resulta difícil comparar estos resultados en el contexto con otras provincias de Argentina ya que, a conocimiento de los autores, no existen datos publicados al respecto. Desde el punto de vista de la conservación ex situ, es necesario a corto plazo iniciar estudios de tolerancia a desecación de semillas en Salix humboldtiana, Sapindus saponaria, Tabebuia nodosa, Jodina rhombifolia y Acanthosyris falcata. Analizando la distribución geográfica de los recursos fitogenéticos, deberían priorizarse para los departamentos del norte de la provincia diferentes estrategias de conservación in situ y ex situ, dada la diversidad y riqueza de sus recursos fitogenéticos.

Las especies mejor representadas en nuestro Banco son las de interés forrajero, ya que son con las que más se ha trabajado y en la que se han desarrollado programas de mejoramiento genético (Pensiero y Zabala, 2017; Pensiero et al., 2017; Marinoni et al., 2019; Marinoni et al., 2019a). En los últimos años han comenzado colectas y estudios de especies de interés apícola, forestal y paisajístico (Cerino et al., 2015; Biganzo- li et al., 2018; Cerino et al., 2018; Ghio et al., 2018; Castro et al., 2019; Cuffia, 2019), por lo que se espera que se incremente de manera significativa en el corto plazo las entradas de las especies priorizadas para esos usos.

A futuro, desde el punto de vista metodológico, es necesario llevar adelante estrategias de conservación y uso en todo el rango de distribución de las especies. Un buen ejemplo de esto lo constituye el género Prosopis, en el cual Prosopis alba es la especie de mayor interés por sus múltiples usos, creciendo en varias ecorregiones, como el Chaco Húmedo, Chaco Seco, ambas del Gran Chaco Americano y la ecorregión del Espinal. En esta especie, los esfuerzos de colecta y conservación se deben llevar a cabo en todo el rango de distribución de esta especie con el objetivo de conservar la máxima cantidad de variabilidad posible (Versino y Joseau, 2005). Para esto, es necesario realizar convenios de colaboración entre instituciones de las provincias y países donde se distribuye la especie con el fin de colectar, conservar y compartir germoplasma para diversos estudios y programas de introducción a cultivo. Por otro lado, dos de los taxones citados son endémicos de la provincia de Santa Fe (Prosopis hassleri var. nigroides y Prosopis nigra var. ragonesei), es decir que no crecen en otras provincias, por lo que en principio debería ser nuestra responsabilidad conservar y evaluar su germoplasma. En estas especies en particular, es necesario generar información de su potencialidad como forestales u otros usos.

La información relevada en este trabajo será de utilidad en el diseño de estrategias de conservación y uso de los recursos fitogenéticos nativos por parte de investigadores y organismos oficiales provinciales y 


\section{BIBLIOGRAFÍA}

Abraham de Noir F. 1991. Information on the forest seed bank in Santiago del Estero, Argentina. Forest Genetic Resources Information, 19:44-45.

Afonso MV. 2016. Tecnologia de sementes e parâmetros morfofisiológicos na propagação de Tabernaemontana catharinensis A. DC. (Apocynaceae). [Programa de Pós-Graduação em Agrobiologia]. [Universidade Federal de Santa Maria]. RS.

Aizen M, Feisinger P. 1994. Forest fragmentation, pollination and plant reproduction in a Chaco Dry Forest, Argentina. Ecology, 75:330-351.

Alaux C, Allier F, Decourtye A, Odoux JF, Tamic T, Chabirand M, Delestra E, Decugis F, Le Conte Y, Henry M. 2017. A 'Landscape physiology'approach for assessing bee health highlights the benefits of floral landscape enrichment and semi-natural habitats. Scientific Reports, 7: 1-10.

Alzugaray C, Carnevale N. 2009. Libro de semillas de especies leñosas autóctonas (Chaco Húmedo: Cuña Boscosa Santafesina). Santa Fe: Secretaría de Medio Ambiente, Ministerio de Aguas, Servicios Públicos y Medio Ambiente. 106 pp.

Andrada AC. 2003. Flora utilizada por Apis mellifera L. en el sur del Caldenal (Provincia Fitogeográfica del Espinal), Argentina. Rev. Mus. Argentino Cienc. Nat. 5:329-336.

Basey AC, Fant JB, Kramer AT. 2015. Producing native plant materials for restoration: 10 rules to collect and maintain genetic diversity. Native Plants Journal 16:37-53.

Basilio AM, Noetinger M. 2002. Análisis polínico de mieles de la región chaqueña: comparación del origen floral entre las zonas; domo central y esteros, cañadas y selvas de ribera. RIA 31:127-134.
Basilio AM, Romero EJ. 1996. Contenido polínico en las mieles de la región del Delta del Paraná (Argentina). Darwiniana 34:113-120.

Benassi A. 2015. Ciudad Botánica, oasis del desierto urbano. La Plata: Ediciones UNLP. 144 pp. (http://sedici.unlp.edu.ar/handle/10915/52387, fecha de ingreso 24/04/2020).

Biganzoli M, Castro DC, Ghio N, Gabriel P, Álvarez N, Derita M, Buyatti M. 2018. Enraizamiento de estacas de especies nativas con potencial ornamental. $40^{\circ}$ Congreso Argentino de Horticultura, Córdoba del 2 al 5 de octubre de 2018.

Botto JY, Mata D. 2014. Investigación científica y plantas ornamentales. Una mirada al futuro. Ciencia Hoy 23:37-44.

Burgueño G, Nardini C. 2017. Diseño de Espacios Verdes sustentables con plantas autóctonas. Buenos Aires: Ed. Albatros. 191pp.

Burgueño G, Nardini C. 2019. Plantas nativas Rioplatenses para el diseño de Espacios Verdes. Introducción al Paisaje Natural. Parte II. Orientación Gráfica Editora. 274p

Burgueño G. 2014. Restauración del paisaje metropolitano. Apuntes para la reflexión y planificación en la Región Metropolitana de Buenos Aires. Buenos Aires: Orientación Gráfica Editora. 288pp.

Cabrera M. 2006. Caracterización polínica de las mieles de la provincia de Formosa, Argentina. Rev. Mus. Argentino Cienc. Nat. 8:135-142.

Cabrera M, Andrada A, Gallez L. 2013. Floración de especies con potencial apícola en el Bosque Nativo Formoseño, Distrito Chaqueño Oriental (Argentina). Bol. Soc. Argent. Bot. 48:477-491

Caccavari M, Fagúndez G. 2010. Pollen spectrum of honeys from the Middle Delta of the Paraná River (Argentina) and their environmental relationship. Span. J. Agric. Res. 8:42-52. 
Carreras ME, Ruiz GM, Bossa S, Planchuelo AM. 2003. Desarrollo de una base de datos con especies de dicotiledóneas nativas de valor ornamental. XXIX Jornadas Argentinas de Botánica. Bol. Soc. Argent. Bot. 38 (Supl.), 253 p.

Carvalho LRD, Silva ED, Davide AC. 2006. Classificação de sementes florestais quanto ao comportamento no armazenamento. Rev. Bras. de Sementes 28:15-25.

Castro D, Abelvey E, Richard G, Gabriel P, Alvarez N, Buyatti M, Gariglio N. 2019. Estadios fenológicos de desarrollo en “ñangapirí” (Eugenia uniflora L.) de acuerdo a la escala BBCH. FAVE Sección Ciencias Agrarias 17:7-21.

Cerino MC, Richard GA, Torretta JP, Gitiérrez HF, Pensiero JF. 2015. Reproductive biology of Ziziphus mistol Griseb. (Rhamnaceae), a wildfruit tree of saline environments. Flora 211: 18-25.

Cerino MC, Castro DC, Richard GA, de Luján Exner E, Pensiero JF. 2018. Functional dioecy in Gleditsia amorphoides (Fabaceae). Aust. J. Bot. 66:85-93.

Convenio de Diversidad Biológica. 1992. Naciones Unidas. https://www.cbd.int/doc/legal/ cbd-es.pdf (Fecha de consulta, 21/03/2020).

Cremaschi, A, van Zwanenberg P. 2020. Bioleft: open-source seeds for low-input farming systems. Journal of Fair Trade 2: 39-43.

Cuffia C. 2019. Biología reproductiva de Trixis praestans (Asteraceae), un recurso invernal para la apicultura. Tesina de grado. Facultad de Humanidades y Ciencias, Universidad Nacional del Litoral.

Dalmazzo M. 2010. Diversidad y aspectos biológicos de abejas silvestres de un ambiente urbano y otro natural de la región central de Santa Fe, Argentina. Rev. Soc. Entomol. Argent. 69 (1-2): 33-44

Dalmazzo M, Vossler FG. 2015. Assessment of the pollen diet in a wood-dwelling augochlorine bee (Halictidae) using different approaches. Apidologie 46: 478-488. https://doi. org/10.1007/s13592-014-0337-7
Da Silva FS. 2010. Qualidade de sementes e produção de mudas de Sideroxylon obtusifolium (SAPOTACEAE) de duas procedências. [Doctoral dissertation]. [Universidade Federal da Paraíba] UFPB.

Danner N, Molitor AM, Schiele S, Härtel S, Steffan-Dewenter I. 2016. Season and landscape composition affect pollen foraging distances and habitat use of honey bees. Ecol. Appl. 26:1920-1929.

De la peña MR, Pensiero JF. 2017. Las plantas como recurso alimenticio de las aves. Santa Fe: Ediciones UNL. 294 pp.

de Boef WS, Subedi A, Peroni N, Thijssen N, O’Keeffe S. 2013. Community Biodiversity Management: promoting resilience and the conservation of plant genetic resources. Routledge, UK. 456 pp.

Decourtye A, Mader E, Desneux N. 2010. Landscape enhancement of floral resources for honey bees in agro-ecosystems. Apidologie 41:264-277.

Demaio P, Karlin UO, Medina M. 2002. Árboles Nativos del centro de Argentina. Buenos Aires: ed. LOLA. 210 pp.

Endler, JA. 1986. Natural selection in the wild (No. 21). UK: Princeton University Press. 339pp.

Fagúndez G, Reinoso P, Aceñolasa P. 2016. Caracterización y fenología de especies de interés apícola en el Departamento Diamante (Entre Ríos, Argentina). Bol. Soc. Argent. Bot. 51:243-267.

Fagúndez GA. 2011. Estudio de los recursos nectaríferos y poliníferos utilizados por Apis mellifera L. en diferentes ecosistemas del Departamento Diamante (Entre Ríos, Argentina). [Tesis Doctoral] [Universidad Nacional del Sur]. Bahía Blanca.

Flores FF, SÁNCHEZ AC. 2010. Primeros resultados de caracterización botánica de mieles de Tetragonisca angustula Latreille (Apidae, Meliponinae) criadas en la localidad Los Naranjos - Orán - Salta. Bol. Soc. Argent. Bot. 45:81-91. 
Girard F, Frison C. 2018. Introduction: Commoning the seeds: The future of agrobiodiversity and food security. In: The Commons, Plant Breeding and Agricultural Research. Challenges for Food Security and Agrobiodiversity; Girard, F., Frison, C., Eds.; Routledge: London, UK, pp. 1-20.

Ghio N, Buyatti M, Marinoni L, Biganzoli M, Gabriel P, Castro D. 2018. Evaluación del comportamiento germinativo de especies nativas con potencial ornamental del centro-norte santafesino. $40^{\circ}$ Congreso Argentino de Horticultura, Córdoba del 2 al 5 de octubre de 2018.

Gori G. 1965. La Forestal: la tragedia del quebracho colorado. Buenos Aires: Ed. Platina/ Stilcograf. 183 pp.

Goulson D, Nicholls E, Botías C, Rotheray EL. 2015. Bee declines driven by combined stress from parasites, pesticides, and lack of flowers. Science 347: 1-16.

Haene E, Araricio G. 2009. 100 árboles argentinos. Buenos Aires: $1^{\text {a }}$ ed. Editorial Albatros. 128 pp.

Haene E. 2007. 100 flores argentinas. Buenos Aires: $1^{\text {a }}$ ed. Editorial Albatros. 128pp.

Hong TD, Ellis RH. 1996. A protocol to determine seed storage behaviour. Roma: International Plant Genetic Resources Institute. 64 pp.

Hong TD, Linington S, Ellis RH. 1996. Seed storage behavior: A compendium. Handbook for Genebanks $N^{\circ}$ 4. Italia: International Plant Genetic Resources Institute. 656 pp.

Hurrell JA, Lahitte HB. 2003. Biota rioplatense VIII. Arbustos 1 Nativos y exóticos. Buenos Aires: LOLA. 263 pp.

Hurrell JA, Bazzano DH, Delucchi G. 2004. Biota rioplatense IX. Arbustos 2 Nativos y exóticos. Buenos Aires: LOLA. 288pp.

Khoury CK, Amariles D, Soto JS, Diaz MV, Sotelo S, Sosa CC, Ramírez-Villegas J, Achicanoy HA, Velásquez-Tibatá J, Guarino L, León B. 2019. Comprehensiveness of conservation of useful wild plants: An operational indicator for biodiversity and sustainable development targets. Ecological Indicators 98:420-429.
Knapp S. 2017. People and plants-the unbreakable bond. Humanos y Plantas-El vínculo indestructible. Conferencia Plenaria. Boletín de la Sociedad Argentina de Botánica. Volumen 52. Pp 86-87. https://botanicaargentina. com.ar/wp-content/uploads/2017/09/SAB2018.pdf. (Fecha de ingreso 24/04/2020).

Li J, van Bueren ETL, Leeuwis C, Jiggins, J. 2014. Expressing the public value of plant genetic resources by organising novel relationships: the contribution of selected participatory plant breeding and market-based arrangements. Journal of Rural Studies 36: 182-196.

Magyp. 2009. https://www.magyp.gob.ar/sitio/ areas/cambio_rural/boletin/07_apicultura. php. (Fecha de visita 24/04/20)

Maldonado L, Marcinkevicius K, Borelli R, Gennari G, Salomón V, Isla MI, Vera N, Borelli V. 2018. Differentiation of argentine propolis from different species of bees and geographical origins by UV spectroscopy and chemometric analysis. Journal of the Saudi Society of Agricultural Sciences 2018: 185-191.

Marinoni L, Zabala JM, Taleisnik EL, Schrauf GE, Richard G, Tomas PA, Giavedoni J, Pensiero JF. 2019. Introducción a cultivo de forrajeras halófitas silvestres de Argentina: aspectos claves para su mejoramiento genético. En: Taleisnik EL, Lavado R. Suelos Afectados por sales, con énfasis en Argentina. Orientación Gráfica Editora. Pp 48-74.

Marinoni LD, Zabala JM, Taleisnik EL, Schrauf GE, Richard GA, Tomas PA, Giavedoni JA, Pensiero JF. 2019. Wild halophytic species as forage sources: key aspects for plant breeding. Grass and Forage Science 74:321-44.

Medeiros ACS, Eira MTS. 2006. Comportamento fisiológico, secagem e armazenamento de sementes florestais nativas. Colombo (PR): Embrapa Florestas. 13 pp.

Menini OJM, Burgueño G. 2018. Plantas Nativas, Las especies y su cultivo. Buenos Aires: Ediciones Jardín. Editorial Catapulta. 215 pp.

| Revista FAVE - Ciencias Agrarias 20 (1) 2021 
Ministerio de Producción de la Provincia de Santa Fe. 2009. Estrategia Provincial para el Sector Agroalimentario (EPSA). Resoluciones del Ministerio de Producción $N^{\circ} 140$ y 187/09. http://www.prosap.gov.ar/webDocs/ EPSA_SantaFeyResolucion_2009.pdf (Fecha de visita: 22/03/2020).

Miranda D, Perea M, Magnitskiy S. 2009. Propagación de especies pasifloráceas. Cultivo, poscosecha y comercialización de las pasifloráceas en Colombia: maracuyá, granadilla, gulupa y curuba. Sociedad Colombiana de Ciencias Hortícolas, Bogota, 69-96.

Morisigue D, Mata D, Facciuto G, Bulrich L. 2012. Floricultura. Pasado y presente de la Floricultura Argentina. Instituto de Floricultura. Buenos Aires: Ediciones INTA.

Naselli C. 1978. El diseño del paisaje. Sumarios (Buenos Aires) 25/26: 253.

Naug D. 2009: Nutritional stress due to habitat loss may explain recent honeybee colony collapses. Biol Conserv 142:2369-2372.

Ollerton J, Erenler H, Edwards M, Crockett R. 2014. Extinctions of aculeate pollinators in Britain and the role of large-scale agricultural changes. Science 346: 1360-1362.

Ostrom E. 2009a. El gobierno de los bienes comunes: la evolución de las instituciones de acción colectiva (No. E14-295). FCE; UNAM; CRIM; IIS.

Ostrom E. 2009b. A general framework for analyzing sustainability of social-ecological systems. Science, 325: 419-422.

Palacios R, Brizuela M. 2005. Prosopis: Historia y elementos para su domesticación. Agrociencia 1/2:41- 51.

Pensiero J, Zabala JM. 2017. Recursos fitogenéticos forrajeros nativos y naturalizados para los Bajos Submeridionales: prospección y priorización de especies para planes de introducción a cultivo. Revista FAVE - Secc. Cs. Agrarias 16:67-98.
Pensiero JF, de la Peña MR. 1999. Flora y Avifauna de la provincia de Santa Fe. Santa Fe: Talleres gráficos El Litoral Argentino. 384 pp. Pensiero JF, Gutiérrez HF, Luchetti AM, Exner E, Kern V, Brnich E, Oakley l, Prado D, Lewis JP. 2005. Flora vascular de la provincia de Santa Fe. Claves para el reconocimiento de las familias y géneros. Catálogo sistemático de las especies. Santa Fe: Ediciones UNL. 403 pp.

Pensiero JF, Zabala JM, Marinoni L, Richard G. 2017. Recursos fitogenéticos forrajeros nativos y naturalizados (RFNyN) para suelos salinos de la región chaqueña de Argentina. En: Taleisnik E y Lavado R eds. La salinidad y alcalinidad en suelos de la Argentina y su efecto sobre vegetación natural y cultivos. Prospección y manejo para su aprovechamiento productivo. Orientación Gráfica Editora, Córdoba, Argentina. Pp 373-419.

Pensiero JF. 2017. Guía de reconocimiento de herbáceas del Chaco Húmedo. Características para su manejo. Buenas prácticas para una ganadería sustentable. Kit de extensión para las Pampas y Campos. Buenos Aires: Fundación Vida Silvestre \& Aves Argentinas. 112 pp.

Piattoni RN. 2010. Cadena de valor de la foresto industria de la región centro: muebles, construcciones y remanufacturas de madera. Informe Final. Consejo Federal de Inversiones. https://www.bcsf.com.ar/ces/downloads.php?file=UkNfMjAxMl9GLnBkZg\%3D\%3D (fecha de visita 22/03/2020).

Rabaglio M, Castignani H, Sanchez C, Barberis N, Huerta G. 2015. Exportaciones Apícolas de Argentina. Programa Nacional Apícola. Buenos Aires: Instituto Nacional de Tecnología Agropecuaria. 24 pp.

Ragonese AE, Milano VA. 1984. Vegetales y substancias tóxicas de la flora Argentina. Enciclopedia Argentina de Agricultura y Jardinería. $2^{\circ}$ ed, Tomo II, Ed ACME. 413 pp. 
Royal Botanic Gardens Kew. (2020) Seed Information Database (SID). Version 7.1. Available from: http://data.kew.org/sid/ (Fecha de visita: 23/03/2020).

Salgado CR, Pieszko G, Tellería MC. 2014. Aporte de la melisopalinología al conocimiento de la flora melífera de un sector de la Provincia Fitogeográfica Chaqueña, Argentina. Bol. Soc. Argent. Bot. 49:513-524.

Salomão AN, Walter BM, Cavalcanti TB, de Medeiros MB, dos Santos IR, Santos AA, dos Santos GP, Mundim RC, Pereira JB, Rezende JM, Moreira GA. 2005. Desenvolvimento de metodologias para a conservação de germoplasma semente resgatado em áreas de aproveitamento de cinco hidrelétricas no Bioma Cerrado. Brasilia: Embrapa Recursos Genéticos e Biotecnologia. Documentos. 138 pp.

Sánchez AC, Lupo LC. 2011 Origen botánico y geográfico de las mieles de El Fuerte, Departamento de Santa Bárbara, Jujuy, Argentina. Bol. Soc. Arg. Bot 46:105-111.

Santangelo F, Gil F. 2016. Potencial productivo de la ganadería bovina de la provincia de Santa Fe. http://www.ipcva.com.ar/documentos/1620_1473257551_potencialproductivodelaprovinciadesantafe.pdf (Fecha de visita 21/03/2020).

Sautu A, Baskin JM, Baskin CC, Condit R. 2006. Studies on the seed biology of 100 native species of trees in a seasonal moist tropical forest, Panama, Central America. Forest Ecology and Management: 234: 245-263.

Sawaya A, Cunha I, Marcucci MC, Oliveira RodriguesR, Eberlin M. 2006. Brazilian Propolis of Tetragonisca angustula and Apis mellifera. Apidologie 37:398-407.

Sievers-Glotzbach, S., Tschersich, J., Gmeiner, N., Kliem, L., \& Ficiciyan, A. (2020). Diverse Seeds-Shared Practices: Conceptualizing Seed Commons. International Journal of the Commons, 14: 418-438.
Silvestri LC. 2015. La conservación de la diversidad genética argentina: tres desafíos para implementar el régimen de acceso a los recursos genéticos y la distribución de los beneficios. Ecología Austral 25:273-278.

Singh A, Dubey PK, Chaurasia R, Dubey RK, Pandey KK, Singh GS, Abhilash PC.2019. Domesticating the Undomesticated for Global Food and Nutritional Security: Four Steps. Agronomy 9:491-599.

Smith S. 2017. Regional native seed cooperatives: working toward available, affordable, and appropriate native seed. Native Plants Journal, 18: 126-134.

Somerville D. 2010. Wintering bees. Primefacts 998: 1-3. https://www.dpi.nsw.gov. au/_data/assets/pdf_file/0011/331697/Wintering-bees.pdf. (Fecha de visita 24/04/20)

Steinhauer NA, Rennich K, Wilson ME, Caron DM, Lengerich EJ, Pettis JS, Rose R, Skinner JA, Tarpy DR, Wilkes JT, Vanengelsdorp D. 2014. A national survey of managed honey bee 2012-2013 annual colony losses in the USA: results from the Bee Informed Partnership. J Apicult Res 53:1-18.

Street K, Bari A, Mackay M, Amri A. 2016. How the focused identification of germplasm strategy is used to mine plant genetic resources collections for adaptive traits. En: Maxted, N., Dulloo, ME, Ford-Lloyd, BV, Eds. Enhancing Crop Genepool Use: Capturing Wild Relative and Landrace Diversity for Crop Improvement. Pp 54-63.

Tamame MA 2011 Estudio de la composición, disponibilidad y calidad de los recursos apícolas del noroeste de La Pampa, provincia fitogeográfica del Monte (República Argentina). [Tesis Doctoral]. [Facultad de Ciencias Naturales y Museo, Universidad Nacional de la Plata]. La Plata. 
Tellería MC. 1995. Plantas de importancia apícola del Distrito Oriental de la Región Pampeana (Argentina). Bol. Soc. Argent. Bot. 30:131-136.

Tosi EA, Ciappini MC, Cazzolli AF, Tapiz LM. 2006. Physico chemical characteristics of propolis collected in Santa Fe (Argentine). APIACTA 41: 110-120.

Vaudo A, Tooker JF, Grozinger CM, Patch HM. 2015. Bee nutrition and floral resource restoration. Curr. Opin. Insect Sci. 10:133-141.

Vazquez F, Castignani H. 2019. El Mercado Apícola. En: Cadena Apícola. Informe de Coyuntura Mensual. Ministerio de Producción y Trabajo, Presidencia de la Nación. Síntesis Apícola n²184,

Vázquez F, Castignani, H. 2018. El Mercado Apícola, Ministerio Agroindustria - INTA. http://www.alimentosargentinos.gob.ar/ HomeAlimentos/Apicultura/documentos/ MIELn178ANEXO.pdf. Fecha de visita (24/04/20).

Vernooy R, Sthapit B, Otieno G, Shrestha P, Gupta A. 2017. The roles of community seed banks in climate change adaption. Development in Practice, 27: 316-327.

Verzino G, Joseau MJ. 2005. El Banco Nacional de Germoplasma de Prosopis: conservación de recursos forestales nativos en Argentina. Córdoba: Ed. UNC 1 ${ }^{\text {a }}$ ed. 172 pp.

Vossler FG. 2015. Broad protein spectrum in stored pollen of three stingless bees from the chaco dry forest in South America (Hymenoptera, Apidae, Meliponini) and its ecological implications. Psyche 2015:1-7.
Weinstein Teixeira E, Negri G, Meira R, Message $\mathrm{D}$, Salatino A. 2005. Plant origin of green propolis: bee behavior, plant anatomy and chemistry. Evidence-based complementary and alternative medicine 2:85-92.

Wolter H, Sievers-Glotzbach S. 2019. Bridging traditional and new commons: the case of fruit breeding. International Journal of the Commons 13: 303-328.

Zabala JM, Pensiero JF, Forni M, Sosa N, Testa M, Giavedoni J, Aiello F, Yost A. \& Quarin P. 2015. Valorización de los recursos fitogenéticos a través de pequeñas empresas productoras de semillas de forrajeras nativas: evaluación de algunos factores que afectan la producción de semillas en leguminosas forrajeras. En Red de Cultivos no Tradicionales de Agricultura Familiar. XVII Foro de Decanos de Facultades de Agronomía del Mercosur, Bolivia y Chile. UNER, pp 65-73.

Zarrilli A. G. 2018. El bosque perdido. Una historia ambiental del norte santafesino (18902010). En: El norte forestal: estudios sobre el territorio santafesino. Edición para el Ministerio de Gobierno y Reforma del Estado de la Provincia de Santa Fe. Pp 17-36. http://redaf. org.ar/version-digital-del-libro-el-norte-forestal-estudio-sobre-el-territorio-santafesino/ (Fecha de visita, 22/03/2020).

Zuloaga FO, Belgrano M, Zanotti CA. 2019. Actualización del catálogo de las planas vasculares del Cono Sur. Darwiniana 7:208-278. 